\title{
Implicaciones del fenómeno publicitario en la configuración del espacio urbano contemporáneo Caso de estudio: Zona de Chapultepec, Guadalajara, Jalisco, México
}

\author{
Implications of the advertising phenomenon in the configuration \\ of contemporary urban space. Case in study: Chapultepec Area, \\ Guadalajara, Jalisco, Mexico
}

Omar Alejandro Ruíz Gutiérrez ${ }^{1}$

Vinculación

Primera versión recibida en: 28 abril, 2017

última versión recibida en: 13 julio, 2017

\section{Resumen}

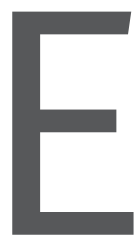

n la ciudad contemporánea, el fenómeno publicitario, entendido como el despliegue de estrategias, imágenes, campañas, frases, mensajes y demás artilugios persuasivos con el objetivo de vender o dar a conocer mensajes o productos, ha venido ocupando una posición relevante en la forma en la que las urbes de nuestros días son concebidas. El fenómeno publicitario prácticamente envuelve muchas de las circunstancias que definen las características de los lugares y las personas

1 Universidad de Guadalajara, Jalisco, México, correo electrónico: omar.rgutierrez@academicos.udg.mx

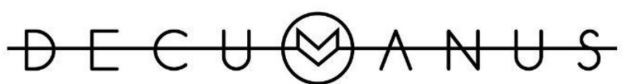

REVISTA INTERDISCIPLINARIA SOBRE ESTUDIOS URBANOS que habitan los espacios urbanos contenidos en las ciudades.

Si bien, la actividad comercial forma parte del funcionamiento básico de la sociedad en general, este tipo de acciones han tenido que adecuarse al dinamismo de un mercado de consumo y consumismo que es impulsado precisamente por la implementación de estrategias y acciones del orden publicitario, tanto a pequeña como a gran escala, que buscan generar la vigencia de las marcas, los productos y los servicios que se ofrecen a una masa de ciudadanos identificados como consumidores, a través de discursos publicitarios cuyo interés fundamental es generar desequilibrios emocionales en los individuos con la finalidad de impulsar cambios en su conducta de consumo.

Para cumplir con lo anterior, se requiere necesariamente de un lugar que sirva de soporte para el despliegue de 
campañas, anuncios y promociones propias del fenómeno publicitario.

En la actualidad, cualquier objeto cuyas dimensiones permitan o posibiliten su identificación visual con cierta ventaja para ello, se convierte en una opción viable para la colocación de diversos instrumentos de persuasión publicitaria. Esta utilización sin restricción de objetos diversos, también considera el uso y disposición de aquellos que son entendidos como elementos que dan forma y sentido a espacios urbanos, sobre todo de aquellos que por su relevancia social y comercial ocupan una posición de referencia en la opinión de los ciudadanos.

Palabras clave: espacio urbano, fenómeno publicitario, consumismo

\section{Abstract}

In the contemporary city, the advertising phenomenon, understood as the deployment of strategies, images, campaigns, phrases, messages and other persuasive devices with the aim of selling or making known messages or products, has been occupying a relevant position in the way which the cities of our days are conceived. The advertising phenomenon practically involves many of the circumstances that define characteristics of the places and people that inhabit urban spaces contained in the cities.

Although commercial activity is part of the basic functioning of society in general, this type of actions have had to adapt to the dynamism of a market of consumption and consumerism that is driven precisely by the implementation of strategies and actions of the advertising order, both to small and large-scale, that seek to generate the validity of brands, products and services offered to a mass of citizens identified as consumers, through advertising speech whose fundamental interest is to generate emotional imbalances in individuals for the purpose of driving changes in their consumption behavior. To comply with the above, necessarily requires a place that serves as a support for the deployment of campaigns, advertisements and promotions of the advertising phenomenon.

In the case of cities such as Guadalajara, the existence and transcendence of certain urban spaces is due to a use that the inhabitants themselves provide in relation to their interests and objectives. This relevance that the same citizen grants, is also identified as a business opportunity for companies seeking to meet their economic needs, which are linked directly with their own permanence in the commercial field.

This document identifies some of the most important implications that the advertising phenomenon generates in an urban space representative of the city of Guadalajara: the Chapultepec Zone. To do so, a methodology is used that includes a commercial survey of the area, analysis of the opinions of pedestrians in the study area, social network users, as well as contributions from previous studies linked to commercial growth. In the final part of the document there are a series of reflections that show a common thread: the mercantile criterion above all things.

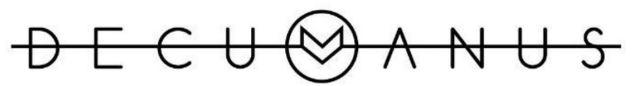

REVISTA INTERDISCIPLINARIA SOBRE ESTUDIOS URBANOS 
Keywords: Urban space, advertising phenomenon, consumerism

\section{Sumario}

- Introducción

- El problema de investigación

- Definiciones conceptuales

- El espacio humano

- La acción social

- El factor humano

- El espacio físico

- Las experiecias colectivas

- El signo y la significación

- El signo publicitario

- El signo arquitectónico

- La globalización

- La transformación económica de la ciudad.

- Perspectiva histórica del fenómeno publicitario en el espacio urbano

- La omnipresencia publicitaria

- Hallazgos

- Resultados

- Levantamiento de negocios existentes en la zona de estudio

- Conclusiones

- Bibliografía

El concepto de espacio urbano asumido como referente para el presente proyecto de investigación se define como "un producto material en relación con otros productos materiales" (Castells, 1974, p. 141). La relevancia de esta definición radica precisamente en una condición de interacción entre los elementos que configuran al espacio urbano, pues a través de esto, lo que existe en ellos propicia la significación de las cosas, y, por ende, trasciende en la percepción del individuo y de las colectividades, a través de objetos materiales.

El espacio urbano, al ser un objeto que forma parte de la realidad tangible e intangible de las ciudades, pone en evidencia la participación humana en la consolidación de las acciones que en él se realizan.

El fenómeno publicitario identificado, ya como una condición omnipresente en el espacio urbano, es un tema por demás relevante en la discusión sobre la ciudad del futuro. "El escenario urbano se ha convertido hoy en día en un claro ejemplo de expresión de las más diversas identidades, no solo grupales sino también individuales" (Baladrón, 2007, p. 76). En este punto es necesario reconocer que la identidad, asumida como experiencia humana, es un indicador que permite ligar lo que acontece en los diferentes espacios urbanos, con estrategias corporativas de organizaciones y empresas que buscan la persuasión del individuo como canal para promover el consumo o la aceptación de ideas y formas de pensar.

Los espacios urbanos de las grandes ciudades son contenedores de manifestaciones y acciones del orden social, comercial y político. La relevancia de cada uno de ellos se genera a partir del surgimiento de dinámicas, acciones, actividades o programas del orden institucional o civil que procuran la utilización de sus características y condiciones para un objetivo particular, tanto individual como colectivo.

En el caso de ciudades como Guadalajara, la existencia y trascendencia de determinados espacios urbanos se debe particularmente al uso que los mismos habitantes le proporcionan

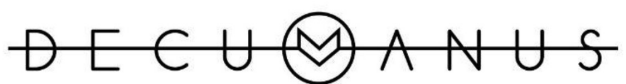

REVISTA INTERDISCIPLINARIA SOBRE ESTUDIOS URBANOS 
en relación con sus intereses y objetivos. Esta relevancia que el mismo ciudadano le otorga es también identificada como una oportunidad de negocio para las empresas que buscan cubrir sus necesidades económicas, las cuales se ligan directamente con su propia permanencia en el ámbito comercial.

Esta identificación de oportunidades, que por lo general se acompaña de cierta flexibilidad o inoperancia de una norma municipal o estatal, requiere de la utilización de cualquier tipo de soporte sin importar horario, condición atmosférica o temporada que permita la disposición de mensajes o anuncios sin mayor regulación que la creatividad con que deben ser presentados, al parecer con limitaciones flexibles. "Los descubrimientos del francés Philippe Lebon o del escocés William Murdoch permitieron que la ciudad se convirtiera en un entorno de luz, un espacio para la socialización día y noche" (Baladrón, 2007, p. 77). La anterior frase aclara el entendimiento de lo que hoy en día sucede en las ciudades y particularmente en los espacios urbanos relevantes, en los que la disposición de elementos persuasivos no parece tener límites en lo que tiempo y espacio se refiere, sobre todo cuando son utilizados precisamente como soportes para el anuncio comercial.

"Si la cultura comercial define el crecimiento de las ciudades, la publicidad, como instrumento fundamental de la sociedad de consumo, garantizará su supervivencia en el contexto urbano" (Baladrón, 2007, p. 89). La relevancia social y comercial de la Zona de Chapultepec se genera principal- mente por la vocación multicultural de la zona, esta última entendida como "una situación de hechos, por la cual colectivos de personas de culturas diferenciadas coexisten en la ciudad" (Baladrón, Martínez y Pacheco, 2007, p. 31). La considerable cantidad de personas con gustos y estilos de vida y de consumo diferenciados en la zona, admite la incorporación de una considerable cantidad de negocios y corporativos que van amalgamando la zona y su estatus social y cultural en función de sus objetivos comerciales.

La presencia de un criterio mercantil en este tipo de lugares, es prácticamente indiscutible, pues la cantidad de individuos que habitan la zona transitan por la misma o acuden a alguna de las actividades diversas que en dicho espacio urbano se organizan, son suficiente argumento para la implementación de artilugios publicitarios de diversas formas y características.

Dos aspectos importantes y ligados con la zona en cuestión justifican la implementación del presente estudio: por un lado, la carga histórica del área y del corredor Chapultepec que es ampliamente documentada por la obra del autor Eduardo López Moreno (2001); por otro, la realización de la Vía Recreactiva, acción social que reúne, de acuerdo con reportes de autoridades locales, a más de doscientas mil personas en los fines de semana en que es organizada.

Si bien la zona ha sido objeto de análisis para diversos enfoques académicos y de investigación, no existe a la fecha un estudio que describa en mayor detalle las implicaciones del fenómeno publicitario en la configuración de este espacio urbano.

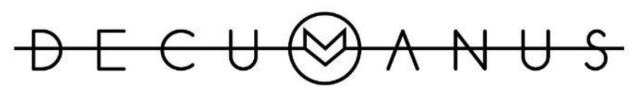

REVISTA INTERDISCIPLINARIA SOBRE ESTUDIOS URBANOS
Núm. 2. Vol. 2. Octubre 2016-Octubre 2017. Instituto de Arquitectura, Diseño y Arte.

Universidad Autónoma de Ciudad Juárez. ISSN: 2448-900X 


\section{El problema de investigación}

En el contexto de las grandes ciudades mexicanas, y particularmente en los espacios urbanos contemporáneos que, por diversos factores o situaciones han adquirido cierto grado de notoriedad y reconocimiento social, existe en su conformación una importante cantidad de elementos que contribuyen a otorgarle un sentido y una vocación más allá de aquellos que son identificados como tradicionales, tanto del lugar como del entorno inmediato en que se encuentran.

Muchos de estos elementos son identificados como parte de un fenómeno publicitario que ha terminado por imponer condiciones a partir de su notable presencia y los intereses que subyacen al mismo. Incluso, en diversos estudios se ha demostrado que la incorporación del fenómeno publicitario a determinados lugares o espacios urbanos de relevancia, lejos de contribuir con el desarrollo integral de los mismos y de la gente que en ellos participa, impone discursos, mensajes y representaciones visuales más bien ligadas a la globalización, al impulso del consumismo y a la desintegración social.

La ciudad se convierte en teatro publicitario, un desfile de mensajes comerciales y marcas, un devenir de persuasión al servicio de intereses de la nueva economía y de los sectores sociales más pujantes de la sociedad. Símbolo de la modernidad, la ciudad es tomada por la publicidad (Baladrón, 2007, p. 80).

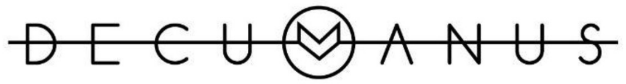

REVISTA INTERDISCIPLINARIA SOBRE ESTUDIOS URBANOS
Para el caso particular de la zona de Chapultepec, existe una notable cantidad de elementos o acciones visuales ligadas o entendidas como parte de un fenómeno publicitario que argumentan la necesidad de llevar a cabo un estudio que permita conocer las implicaciones que dicho fenómeno ha tenido en la configuración urbana de la zona y en la percepción de las personas que transitan por ella. El desconocimiento sobre el proceso que describe la interrelación de la ciudad, el ciudadano y el espacio urbano relevante, muestra un vacío en el entendimiento de los procesos que acontecen en ciertos escenarios de la ciudad contemporánea.

La zona de Chapultepec en Guadalajara posee un importante legado histórico para la ciudad en virtud de ser el escenario que significó el "rompimiento urbano" de un periodo de la historia local, que a su vez contribuyó con "una nueva concepción urbana de la ciudad" (Cordero, Ochoa, Núñez, \& Cordero, 2011). En la actualidad, esta zona se ha posicionado como un corredor cultural que atrae a visitantes locales, nacionales e internacionales, lo cual permite tener una idea sobre las implicaciones económicas que el área tiene para la ciudad.

\section{Definiciones conceptuales}

La delimitación del contexto permite el entendimiento del fenómeno, así como del lugar en que se presenta, lo cual requiere del establecimiento de una lista de definiciones conceptuales sobre otros fenómenos o aspectos que ocurren y se manifiestan a la par del fenómeno publicitario en el área 
de estudio. Su objetivo es establecer una convención sobre el significado de estos conceptos y su interrelación con el objeto de estudio, pues su integración representa un desglose de los elementos que estructuran lo que entendemos como entorno urbano.

\section{El espacio urbano}

"El considerar a la ciudad como la proyección de la sociedad en el espacio es, al mismo tiempo, un punto de partida indispensable y una afirmación demasiado elemental" (Castells, 1974, p. 141). Sin embargo, la descripción necesaria es aquella que considera a todos los elementos que son identificables no solo desde la perspectiva material, sino también de aquellos que son intangibles y que de igual forma se encuentran y conforman al espacio en sí. La definición del espacio que será considerada para el presente estudio hace referencia, como se mencionó, a la postura de Castells que lo define como "un producto material en relación con otros productos materiales" (1974, p. 141). Esta relación trae consigo una serie de cuestionamientos sobre la forma en que dichos productos materiales interactúan entre sí y desarrollan, a partir de su interacción, otras manifestaciones que en conjunto le otorgan al espacio como tal, una forma determinada, una función específica y un significado en particular que evidentemente son asumidos, claro está, dependiendo de las características propias e individuales de los sujetos que en él actúan.

El espacio podría entonces identificarse como un objeto de características reales en el que ocurren y se manifiestan determinadas situaciones que no solo pueden, sino deben ser analizadas a partir del conocimiento objetivo: "El espacio no es tan solo un contenedor donde ocurren las relaciones sociales; es, antes que nada, un producto de la agencia humana, que de manera colectiva va creando y recreando nuevas formas asociativas" (Bueno y Pérez, 2006, p. 9). El espacio asume nuevas circunstancias dependiendo de una serie de factores tanto internos como externos para conformar su nueva dimensión y definición. La incidencia que en este proceso tiene el hombre en su proceso de interacción y desenvolvimiento con su entorno y con los fenómenos o paradigmas existentes, determina sus particularidades.

\section{La acción social}

La acción en el ámbito sociológico se puede entender a partir de Giddens (citado por Bruno Lutz en La acción social en la teoría sociológica: una aproximación, 2010) como: "una interacción social, la cual es una co-presencia de dos o varios agentes", por lo tanto, la acción social puede asumirse como "toda acción individual y/o colectiva que tiene repercusión en el otro y tiene dos elementos: la racionalización y la motivación" (Lutz, 2010).

\section{El factor humano}

Desde la perspectiva etimológica, un factor es entendido como un elemento o circunstancia que, junto con otras, generan o producen un efecto. El factor humano se entiende, por consiguiente, como un conjunto de

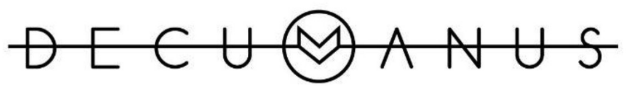

REVISTA INTERDISCIPLINARIA SOBRE ESTUDIOS URBANOS
Núm. 2. Vol. 2. Octubre 2016-Octubre 2017. Instituto de Arquitectura, Diseño y Arte.

Universidad Autónoma de Ciudad Juárez. ISSN: 2448-900X 
causalidades en las que interviene o participa el ser humano.

En esta definición se considera la posible interacción con otros factores de diversa índole, siempre y cuando las circunstancias que permitan su entendimiento o explicación así lo requieran. El factor humano es, por lo tanto, el elemento que permite o posibilita la interacción de los elementos existentes en el espacio urbano. En esta definición caben sus particularidades, su condición social y económica.

\section{El espacio físico}

El entendimiento del concepto espacio fisico requiere del reconocimiento de las cosas tangibles que configuran sus circunstancias como tal. Pero esta definición requiere a la vez de las aportaciones de autores como Otto Friedrich Bollnow, citado por Castreje, Travieso y Zimmermann (2013). Según el autor, "a nivel conceptual el espacio vivencial es en donde se desarrolla y manifiesta la actividad humana". Asimismo, expresa que el término espacio vivido, demuestra que este es "medio de la vida humana" (Castreje, Travieso, \& Zimmermann, 2013). Entonces, el espacio vivido estará impregnado por una serie de significaciones como estructura y ordenación que son expresión de cada grupo social y de cada individuo.

\section{Las experiencias colectivas}

El término experiencia se define como una forma de conocimiento o habilidad derivada de la observación, de la participación y de la vivencia de un evento o de las cosas que suceden. La experiencia colectiva es, por lo tanto, toda aquella forma de conocimiento que experimenta un grupo de individuos a partir de lo que ven, escuchan, observan, exploran o sienten en un determinado momento y espacio geográfico (Ruíz, 2011). El entorno y el contexto son factores que determinan el significado de las cosas y los momentos, los cuales contribuyen con la interpretación de la experiencia, en primer momento individual, y en segundo término grupal.

\section{El signo y la significación}

El signo es el puente que relaciona al sujeto con el mundo y posee tres componentes formales: signo, objeto e interpretante bajo las formas correlativas de discurso, representaciones (espacios mentales) y operaciones. Ante esto, un signo es un elemento del lenguaje o una imagen compuesta de la relación del signo, es decir, un referente (el objeto al que se refiere el signo); el campo de representación (la naturaleza de la relación con el referente), y el interpretante (la relación experimental entre el intérprete y el significado) (Trifonas, 2004).

El signo se refiere a un referente dentro de un campo de representaciones que lo sitúan según su función: a qué se refiere, cómo y para qué finalidad. El significado se produce cuando el lector del signo descodifica el espacio de representación para interpretar la diferencia entre signos a partir de la experiencia (Trifonas, 2004). El signo entonces, es entendido como todo aquello que representa a otra cosa, que está en lugar de otra cosa y, por lo tanto, el significado es la cosa repre-

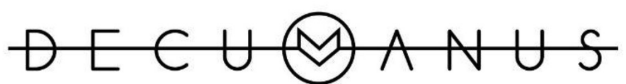

REVISTA INTERDISCIPLINARIA SOBRE ESTUDIOS URBANOS
Núm. 2. Vol. 2. Octubre 2016-Octubre 2017. Instituto de Arquitectura, Diseño y Arte.

Universidad Autónoma de Ciudad Juárez. ISSN: 2448-900X 
sentada. Su uso se da cuando un emisor inicia el proceso de transmisión del mismo a partir de una fuente utilizando un medio o canal y un código susceptible de ruido hacia un receptor en particular.

Según Pierce, citado por Caivano (2005), existe una clasificación de los signos espaciales a partir de las relaciones internas entre los tres aspectos del signo (signo, objeto e interpretante). Si tomamos las relaciones de los signos entre sí, se tienen tres tipos de signos: cualisigno (cualidad), sinsigno (signo singular) y legisigno (ley o convención).

Las relaciones entre signos y objetos dan las clases icono, índice y símbolo. De los signos con los interpretantes resulta: rhema, dicisigno (dicente) y argumento (Caivano, 2005). Por lo tanto, el estudio de los signos en la vida y en la estructura social es la materia prima de la semiología; sus principales objetos de estudio son específicamente el signo, el código y las estructuras que soportan esta acción. En ella, se identifica un proceso de semiosis entendido a partir de Pierce (citado por Eco, 2005).

Significar es un concepto en el cual cabe la interpretación individual: la contextualización donde el ciudadano participa incide en su propia definición, su propia realidad. La descodificación convencional entonces, adquiere una forma o un significado dependiendo de aspectos más cercanos al individuo, de su cultura, de sus condiciones particulares y la forma en que interactúa con su entorno y con los elementos que en él existen.

La significación implica un proceso de interpretación a una represen- tación, entendido esto último, no meramente como plasmación gráfica sino como cualquier modelo o sistema de signos que media con el objeto de conocimiento (Caivano, 2005, p. 114).

Por lo tanto, la representación puede tener diferentes variantes, depende de muchos aspectos que tendrían que ser considerados en la convención de quienes perciben un signo.

\section{El signo publicitario}

El signo publicitario es un discurso con un texto argumentativo; el emisor aporta un conjunto de pruebas o argumentos para orientar la interpretación del receptor a través de diversos elementos persuasivos encaminados a determinar algún tipo de conclusión (Márquez, 2007). Dicha persuasión intenta modificar la conducta de quien recibe la información con la idea de provocar en el receptor un determinado nivel de conducta respecto a algún producto o servicio.

El signo publicitario está directamente relacionado con la comunicación, y como tal, se le reconocen tres fases clave: la información, los afectos y el comportamiento. Todos estos a incidir de manera directa en la persuasión de los individuos. "El desarrollo económico de la sociedad, particularmente a partir de la generación de la clase media" (Márquez, 2007, p. 485), dota de características diferentes a la publicidad como tal, desde ese momento "la función descriptiva de lo existente, adquiere un nueva carga representativa o simbólica" (Márquez, 2007, p. 486) que reconoce un valor so-

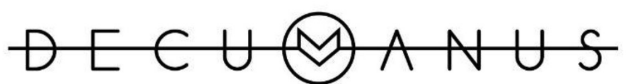

REVISTA INTERDISCIPLINARIA SOBRE ESTUDIOS URBANOS
Núm. 2. Vol. 2. Octubre 2016-Octubre 2017. Instituto de Arquitectura, Diseño y Arte.

Universidad Autónoma de Ciudad Juárez. ISSN: 2448-900X 
cial diferente en cuanto a los artículos u objetos que existen en la actividad económica y la posesión de los mismos. El signo publicitario corresponde con la intencionalidad de imponer un discurso cuya finalidad principal es provocar en el individuo receptor un estado de desequilibrio en cuanto a su estado motivacional, pues de esta circunstancia resulta la modificación de la conducta.

\section{El signo arquitectónico}

La impostación semiótica no impone la caracterización del signo basándose en los comportamientos que estimula ni fundándose en los objetos reales que lo comprueban: "la caracterización de un signo se basa solamente en un significado que un determinado contexto cultural atribuye a un significante" (Eco, 2005, p. 288).

Se reconoce en el signo arquitectónico la presencia de un significante cuyo significado es la función que este hace posible. En los signos arquitectónicos existen significantes descriptibles y catalogables, que pueden denotar funciones precisas, con tal de que sean interpretados por medio de determinados códigos y estos pueden revestir significados sucesivos que, como se verá, podrán serle atribuidos no solamente por vía de denotación, sino también por vía de connotación, basándose en otros códigos (Eco, 2005).

\section{La globalización}

“La globalización del mundo expresa un nuevo ciclo de expansión del capitalismo, como forma de producción y proceso civilizador de alcance mun- dial" (Ianni, 2004, p. 11). Es un proceso que deja en claro el nivel del alcance del fenómeno en la realidad social, misma que representaba, contenía, establecía y ejecutaba procesos dinámicos de expansión hacia todos los aspectos que moldeaban o estructuraban las principales manifestaciones de los individuos, economías, modos de pensar y actuar; es decir, el alcance descrito parece ser avasallador para todas las manifestaciones sociales existentes en la actualidad.

Su esfera, rango de influencia o imposición, contiene a prácticamente todos los grupos sociales, empresas, gobiernos $u$ organizaciones que en la actualidad tengan alguna actividad, determinante o no, en el escenario social, económico y cultural de las naciones. "Este concepto se entendía como una etapa extensiva e intensiva del capitalismo como método de producción y proceso civilizador" (Ianni, 2004, p. 13) que utiliza las condiciones de desarrollo tecnológico y de demanda de productos y servicios, por citar algunos aspectos, para su consolidación a escala global. Sin embargo, y a partir de las condiciones, factores y elementos que van conformando la realidad, surgen nuevas formas de manifestación que describen la manera en que el fenómeno parece seguir impregnando las cuestiones sociales y sus respectivas manifestaciones y comportamientos específicos.

La idea global, por lo tanto, tiene implicaciones de todo orden. "Desde la perspectiva económica y comercial, plantea escenarios sin frontera, un shopping center global donde todo se parece cada vez más a todo" (Ianni, 2006, p. 6) y donde la intención de homoge-

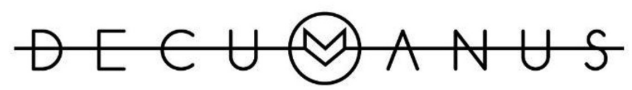

REVISTA INTERDISCIPLINARIA SOBRE ESTUDIOS URBANOS 
neidad abarca no solo lo visual, también, lo correspondiente a la conducta y consumo: las imágenes, costumbres, mensajes, idiomas, modas y demás manifestaciones, que anteriormente eran particularmente descriptivas de determinadas regiones o localidades, sobre todo de sociedades occidentales, proliferan, van moldeando y conformando nuevas formas que los individuos buscan adquirir, sin importar las distancias y las condiciones de los contextos en que se desenvuelven.

La globalización entonces, es un fenómeno que dificilmente tendría una sola definición. Existen narrativas que consideran perspectivas que abarcan la tecnología, la cultura, la política o la economía por citar a los probablemente más importantes aspectos que describen al fenómeno en relación con la realidad actual. Sin embargo, estos aspectos podrían estar inmersos en consideraciones filosóficas.

\section{La transformación económica de la ciudad}

La ciudad de Guadalajara y su Zona Metropolitana, al igual que el resto de las ciudades importantes del país, ha sido influenciada por fenómenos propios de la globalización, que prácticamente han abarcado la gran mayoría de los elementos que la conforman. De manera particular, la presencia y fortalecimiento de negocios, cuya actividad económica se liga directamente con el desarrollo tecnológico, ha consolidado su presencia en los territorios urbanos que han destacado en el ámbito local como centros de concentración urbana.
En una publicación titulada $L a$ transformación económica de la Zona Metropolitana de Guadalajara y su impacto en el espacio urbano, los autores Rodríguez y Cota (2006) exponen los cambios que, desde su perspectiva, argumentan el estado actual de las ciudades en general, sobre todo de aquellas que, por sus dimensiones adquieren mayor notoriedad.

De acuerdo con el artículo, "el nuevo modelo de crecimiento urbano es resultado de dos procesos fundamentales: la globalización de las actividades económicas y el incremento en el uso de los servicios que requieren conocimientos avanzados" (Rodríguez y Cota, 2006, p. 1). Esta afirmación, cuando es contrastada con los resultados obtenidos del levantamiento de negocios existentes en el primer cuadro de actividad comercial de la zona de estudio del presente proyecto de investigación, argumenta sustancialmente lo expuesto por los autores antes mencionados. En relación con esto, el instrumento aplicado generó los siguientes datos: la mayor cantidad de negocios existentes son las oficinas de servicios profesionales, con el $52.15 \%$; seguida por la de restaurantes, $20.63 \%$ y los restaurantes bar, con el $10.88 \%$.

Si bien es cierto que la globalización de la actividad económica es un factor en la transformación urbana de las ciudades y sus diferentes espacios urbanos, también es necesario destacar la aportación de otros fenómenos que actúan de manera importante en la materialización de esta condición. Tal es el caso del fenómeno publicitario, cuya principal función es generar desequilibrios emocionales en los in-

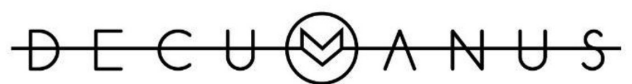

REVISTA INTERDISCIPLINARIA SOBRE ESTUDIOS URBANOS
Núm. 2. Vol. 2. Octubre 2016-Octubre 2017. Instituto de Arquitectura, Diseño y Arte.

Universidad Autónoma de Ciudad Juárez. ISSN: 2448-900X 
dividuos, a través de estrategias persuasivas, con el objetivo de impulsar el consumo de productos o servicios; acción que posibilita adémas, la presencia de unidades de negocio que requieren del consumo de sus servicios para su permanencia y crecimiento.

En el desglose de los cambios que se suscitan por las nuevas formas de producción, Rodríguez y Cota (2006) mencionan dos aspectos fundamentales que encajan de manera perfecta para comprender los procesos que sirven de igual forma en la proliferación de empresas cuya principal actividad económica requiere de la generación de discursos y mensajes persuasivos ligados estrechamente con el fenómeno publicitario: innovación y conocimiento. Estos dos aspectos clave para el desempeño de cualquier tipo de empresa son también cualidades que requieren no solo comunicarse, sino hacerlo de la mejor manera posible. Para ello, se requiere de la creación de escenarios que propicien la comunicación persuasiva, particularmente en los lugares y espacios que propician el encuentro entre el individuo y el producto, y entre ellos, el instrumento que posibilita la interacción.

Actualmente es posible afirmar que las empresas que participan en este modelo económico lo hacen a través de procesos "flexibles, descentralizados y con un incremento en el uso de capital intangible" (Rodríguez y Cota, 2006, p. 3), situación que incide, por ejemplo, en el uso y disposición del territorio urbano.

Por lo tanto, "los territorios experimentan los procesos de concentración y dispersión de empresas y oficinas corporativas que pretender abaratar costos y hacer más eficientes los recursos disponibles" (Rodríguez y Cota, 2006, p. 2). Lo anterior sirve para comprender la aglomeración de ciertas áreas con cierto tipo de interés, dependiendo de sus características fisicas, de accesibilidad y de contacto con el ciudadano. Esta aglomeración aprueba de igual manera la "generación de polos de atracción y de actividades económicas" (Rodríguez y Cota, 2006 , p. 2) que van conformando la oferta de la ciudad como atractivo comercial, cultural o social.

Si se analizan desde una perspectiva amplia los resultados del levantamiento de negocios existentes en la zona de investigación, es posible encontrar una correlación entre la presencia de negocios y los estilos de vida que es posible identificar en el área en cuestión.

En el supuesto de que existan en promedio seis personas empleadas en cada uno de los negocios existentes, independientemente de su giro comercial, la cantidad resultante de multiplicar los 441 negocios por el promedio es de 2646 personas, tan solo como empleados o equipo básico de trabajo. Esta cantidad de individuos, sujetos a un esquema de horario de trabajo de aproximadamente ocho horas diarias, requerirá entonces de otros negocios con productos o servicios cuyo consumo le permita la satisfacción de sus necesidades impuestas en gran medida por el entorno y contexto urbano y a partir de su estilo de vida, el cual, por cierto, determina el tipo de nivel de consumo.

El proceso cotidiano de vida urbana contemporánea permite tener una idea más o menos clara sobre la

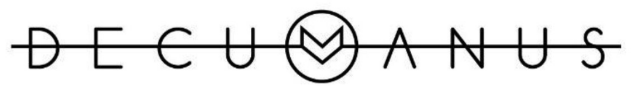

REVISTA INTERDISCIPLINARIA SOBRE ESTUDIOS URBANOS
Núm. 2. Vol. 2. Octubre 2016-Octubre 2017. Instituto de Arquitectura, Diseño y Arte.

Universidad Autónoma de Ciudad Juárez. ISSN: 2448-900X 
importante cantidad de factores que existen en el entorno y el nivel de relevancia e influencia que éstos pueden tener al momento de impulsar la conducta del individuo, y con ello, la configuración del espacio urbano que los contiene en función de sus necesidades e intereses.

En lo referente a la influencia de la nueva economía en la ciudad de Guadalajara, los autores Rodríguez y Cota (2006) exponen:

Cuando la economía global se encaminó a un mayor crecimiento internacional, México procuró no quedarse atrás. La entrada al Acuerdo General de Aranceles y Comercio (GATT por sus siglas en inglés), significó el cambio de modelo económico de nuestro país (Rodríguez y Cota, 2006, p. 5).

Esta incorporación encontró en su primera etapa un cambio en la producción industrial (Rodríguez y Cota, 2006), lo que a su vez generó una demanda de infraestructura y actividades que permitieran dichos procesos productivos. Lo anterior sirvió para incorporar el término de segmentación productiva cuando se hace necesaria la reducción de costos, la especialización de mano de obra y el incremento de desarrollo competitivo.

De acuerdo con estos autores, "es así como surge el desarrollo tecnológico en las comunicaciones, donde el Internet es una herramienta de comunicación y traslado de información" (Rodríguez y Cota, 2006, p.3).

Este proceso de adecuación de la economía no solo impulsa el desarrollo de determinadas áreas geográficas del País en relación con sus particularidades físicas, económicas y políticas, sino que también promueve a una escala menor, la generación de modelos de negocio que buscan obtener provecho de dichas condiciones. Desde una perspectiva a nivel nacional, "la concentración de servicios financieros, la actividad comercial y los servicios profesionales permite a la región centro del país ser el punto nodal de la economía nacional" (Rodríguez y Cota, 2006, p. 3). Esta condición persiste en la actualidad, sobre todo cuando se identifican los principales ejes para la toma de decisiones en el ámbito económico y político, sin embargo, existen casos como el de la ciudad de Guadalajara y su Zona Metropolitana que han logrado consolidar su presencia a nivel nacional a través del incremento de unidades de negocio concentradas en determinadas zonas geográficas y particularmente cuando se involucra la tecnología.

En una publicación reciente del diario local El Informador (2015), ${ }^{2}$ menciona que, por cada mil individuos en el estado de Jalisco, existen 11 empresas registradas y que en comparación con demarcaciones como el Estado de México y Nuevo León, la cifra es notablemente favorable para la ZMG quedando solamente por debajo del Distrito Federal (ahora Ciudad de México), el cual acumulaba, al momento de la publicación, casi 90 mil unidades empresariales contra 82 mil del estado de Jalisco.

Este crecimiento de la actividad económica ciertamente no correspon-

2 http://www.informador.com.mx/jalisco/2010/182075/6/jalisco-la-region-con-mas-empresas.htm

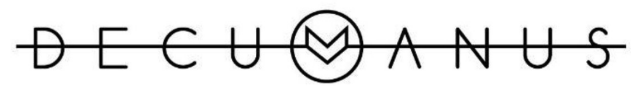

REVISTA INTERDISCIPLINARIA SOBRE ESTUDIOS URBANOS 
de con la categoría de las empresas más importantes que la revista Expansión publicó en 1997, sin embargo, sí es notable el impulso que varios sectores de la industria local tuvieron para generar dichos indicadores que en suma le otorgan el valor actual.

Como parte del argumento que impulsó este crecimiento, los autores mencionan el replanteamiento de las "políticas industriales y el aprovechamiento de las condiciones locales" (Rodríguez y Cota, 2006, p. 3), como las acciones que permitieron generar esta importante condición para la ciudad de Guadalajara. Destacan también el surgimiento de la industria electrónica como un detonador a través de la producción de bienes básicos manufactureros (Rodríguez y Cota, 2006), los cuales requirieron de otros servicios ligados con el giro de la industria, resultando un modelo interesante para el desarrollo económico de la Ciudad y su Zona Metropolitana que incluyó el repunte de la industria electrónica. Este hecho como tal puede interpretarse como el mecanismo que permitió a la Ciudad incorporarse de manera más significativa con el modelo global, lo que evidentemente derivó en la necesidad de establecer nuevos modelos de sinergia para complementar lo que sucedía de cara al futuro. A este respecto, diversos autores señalan que es a través de las empresas y la sinergia existente entre ellas, que se impulsa la materialización de las relaciones con otros territorios y circunstancias.

En lo concerniente con las etapas que permiten el crecimiento de los entornos urbanos, Rodríguez y Cota (2006) exponen que existen cuatro a través de las cuales se manifiesta dicho crecimiento: "urbanización, urbanización-suburbanización, suburbanización y desorganización" (Rodríguez y Cota, 2006, p. 6). Lo anterior es una manera de comprender el proceso de transformación industrial al de servicios, lo que también implica una reestructuración del entorno urbano a partir de las nuevas demandas y necesidades de los actores que mayor presencia e influencia tienen en su contexto. Esta situación evidentemente sugiere importantes grados de afectación para aquellos elementos o unidades que menor nivel de importancia tienen, pero que, sin embargo, contribuyen en gran medida con el contexto económico de la región.

Si bien existen cuatro etapas que permiten el crecimiento urbano, en cualquiera de ellas prevalece el hecho de la concentración de personas en áreas geográficas distintas a la periferia. "Lo anterior se debe a razones de tipo económico, social e histórico" (Rodríguez y Cota, 2006, p. 6).

El precio de suelo es una condición de concentración ya que limita los tipos de zonas habitacionales. En el ámbito social, las diferencias raciales, socioeconómicos, las costumbres y la convivencia barrial hacen que la población se distribuya bajo ciertos criterios. Desde el punto de vista histórico, el mantener una tradición, el conservar un estatus y el ser parte de la historia de la ciudad, mantiene a la población en los espacios tradicionales (Rodríguez y Cota, 2006, p. 6).

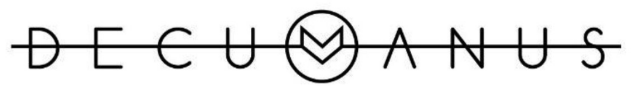

REVISTA INTERDISCIPLINARIA SOBRE ESTUDIOS URBANOS
Núm. 2. Vol. 2. Octubre 2016-Octubre 2017. Instituto de Arquitectura, Diseño y Arte.

Universidad Autónoma de Ciudad Juárez. ISSN: 2448-900X 
Ademas de los factores anteriores, se debe considerar la relevancia que tiene hoy en día aspectos como: "accesibilidad, estructura y equipamiento urbano, factibilidad de construcción y contaminación urbana" (Rodríguez y Cota, 2006, p. 6). Una particularidad del espacio urbano contemporáneo es que, al poseer las características anteriormente señaladas, la posibilidad de trascender por encima de aspectos como el uso de suelo, el ámbito social, así como la perspectiva histórica del lugar, se considera como viable siempre y cuando el factor económico represente una oportunidad de mercado.

La población tiene movilidad de acuerdo a la función de capacidad económica, la percepción social del entorno, el impacto que pueda darse de las externalidades negativas o positivas y las condiciones en que se encuentra la zona con relación a la infraestructura y equipamiento urbano (Rodríguez y Cota, 2006, p. 6).

La concentración económica de la zona de Chapultepec en definitiva ha logrado transformar la estructura urbana de la zona a partir de los nuevos comportamientos de la población que vive en la zona y de aquella que interactúa con ella por algún motivo económico, social o de tradición. Según varios autores reconocidos en el estudio urbano, aspectos como la accesibilidad y la movilidad son condicionantes para impulsar el surgimiento de nuevas centralidades a partir del desarrollo de las principales actividades económicas que en dichos lugares se realizan. El caso particular del área de estudio del presente proyecto de investigación, arroja importantes indicadores que demuestran este tipo de crecimiento y desarrollo.

En lo que respecta al valor comercial de la zona, la anterior imagen muestra los tres niveles de valor del área en cuestión, según el Periódico Oficial del Estado de Jalisco, aprobados el 13 de noviembre de 2014. De acuerdo con esta tabla, en el Distrito 01 "Centro", subdistritos 34 y 22/2, donde se encuentra el área de estudio del presente proyecto, el valor de rango varía de $\$ 3800$ a $\$ 3500$ pesos por metro cuadrado y donde claramente el Norte tiene un valor más alto que en el Sur. El valor de rango es solo un indicador general del costo del $\mathrm{m}^{2}$ dentro de estos dos subdistritos, sin embargo, el valor de calle sobre Avenida Chapultepec Norte a Av. Chapultepec Sur ubicadas dentro del Distrito 1 "Centro", subdistrito 34 22/2; oscila desde los $\$ 9100.00$ a los $\$ 14450.00$ pesos por metro cuadrado "valor catastral" y contrario a su valor de rango, el precio es mayor conforme se acerque al Norte.

El valor puede variar de acuerdo con el tipo de construcción y con la calidad del estado de conservación y con el código de clasificación de la construcción. Por citar un ejemplo, el conjunto de Horizontes Chapultepec, ubicado en Avenida Chapultepec 480 R-08 tiene un valor de rango de $\$ 3800.00$ pesos por $\mathrm{m}^{2}$, un valor de calle de $\$ 9700.00$ pesos por $\mathrm{m}^{2}$ y un valor de 360 millones 793 mil 470 pesos, todo el conjunto. La utilización general del suelo es mixto distrital sobre la Av. Chapultepec Norte y Sur, lo que implica que las zonas habitacionales

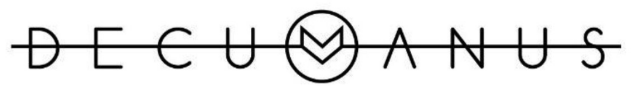

REVISTA INTERDISCIPLINARIA SOBRE ESTUDIOS URBANOS
Núm. 2. Vol. 2. Octubre 2016-Octubre 2017. Instituto de Arquitectura, Diseño y Arte.

Universidad Autónoma de Ciudad Juárez. ISSN: 2448-900X 
Figura 1. Zona de estudio (2015).

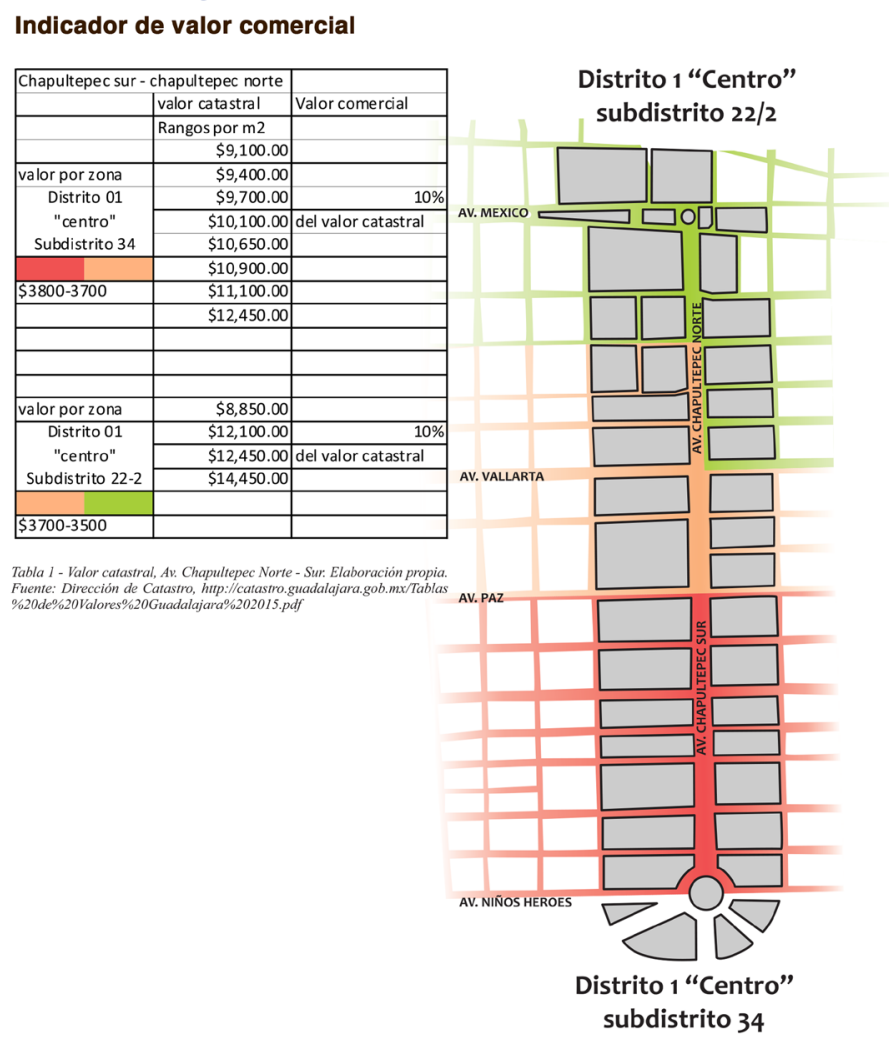

Fuente: Elaboración propia

y comerciales coexistan de manera equilibrada.

De acuerdo con el Directorio Estadístico Nacional de Unidades Económicas (DENUE) ${ }^{3}$ el uso comercial predominante son los bufetes juridicos, ajustadores, gestor de seguros y finanzas; bancas múltiples, cafeterías, restaurantes hacia la Av. Chapultepec Sur y comercio al por menor de vestimenta regional y vestidos de novia; comercio al por menor de telas, bares y similares hacia el Norte. Por las características del uso del suelo, el valor catastral y el valor comercial que es $10 \%$ del valor catastral de la zona, los indicadores de marginación son

3 México: Inegi, 2014. muy bajos y los niveles socioeconómicos según la variable de la Asociación Mexicana de Inteligencia de Mercado y Opinión Pública (AMAI) de la zona están por arriba del nivel C-, un claro ejemplo son los proyectos de los alrededores cuyos precios de venta están arriba de millón de pesos.

Los datos descritos en las tablas anteriores permiten evidenciar el crecimiento comercial y económico de la zona de Chapultepec desde sus inicios. La ciudad de Guadalajara, aún con una tendencia monocéntrica de sus funciones, muestra también una disminución importante de esta situación. A la par de lo que acontece con muchas ciudades importantes en el mundo, las nuevas dinámicas de infraestructura y

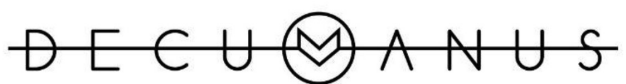

REVISTA INTERDISCIPLINARIA SOBRE ESTUDIOS URBANOS 
La siguiente tabla muestra el levantamiento comercial de la zona de estudio:

Tabla 1. Levantamiento comercial. Av. Chapultepec Norte - Sur

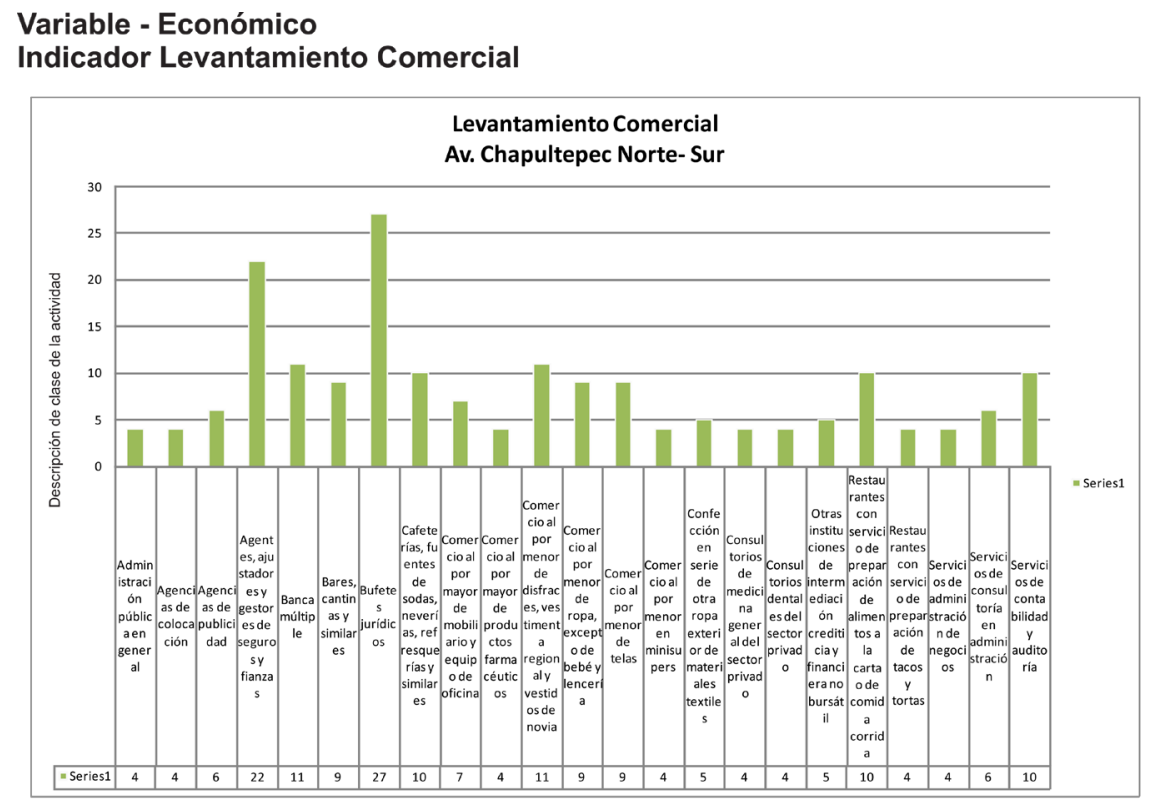

Nota: Las actividades de esta tabla son las más representativas en la avenida Chapultepec Norte-sur. Excluyendo de esta tabla151 giros para fines practicos.

Fuente: Elaboración propia. Censos económicos 2014. Inegi. Denue, http://gaia.inegi.org.mx/ mdm6/?v=bGF00jlwLjY2ODQyLGxvbjotMTAzLjM2ODQ5LHo6MTQsbDpjZGVudWUxNA--

funcionalidad impulsan el desarrollo de nuevas centralidades en espacios con mejores condiciones para destacar desde perspectivas como la económica, tecnológica, social y cultural.

Para detectar y entender la evaluación que ha tenido la ciudad en cuanto a sus centros económicos se utilizó el índice de centralidad para los años 1985, 1993 y 1998, encontrando en un primer momento, que el centro tradicional es el polo donde se ubican las actividades de mayor impacto, en un segundo momento se da una expansión del área (centralidad expandida según Mattos, 1998), y finalmente, en un tercer momento, la reubicación de estas actividades en otros lugares, reduciendo su centro, creando islas económicas, y dándose un aparentemente aprovecha- miento de otros centros (Rodríguez y Cota, 2006, p. 18).

La ciudad de Guadalajara, desde sus inicios, desarrolló principalmente el abastecimiento de bienes y servicios hacia importantes regiones del País. Con el paso del tiempo y el surgimiento de la manufactura se crearon nuevos espacios industriales, particularmente en las afueras de la ciudad. La apertura comercial a nivel internacional repercutió en la industria manufacturera, lo que implicó una expansión hacia los municipios conurbados.

Al insertarse la actividad manufacturera en la estructura económica de la ciudad, dio como resultado la creación de espacios industriales, la migración del campo a la ciudad y la creación de infraestructura y

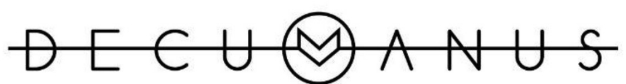

REVISTA INTERDISCIPLINARIA SOBRE ESTUDIOS URBANOS 
Implicaciones del fenómeno publicitario en la configuración del espacio urbano contemporáneo

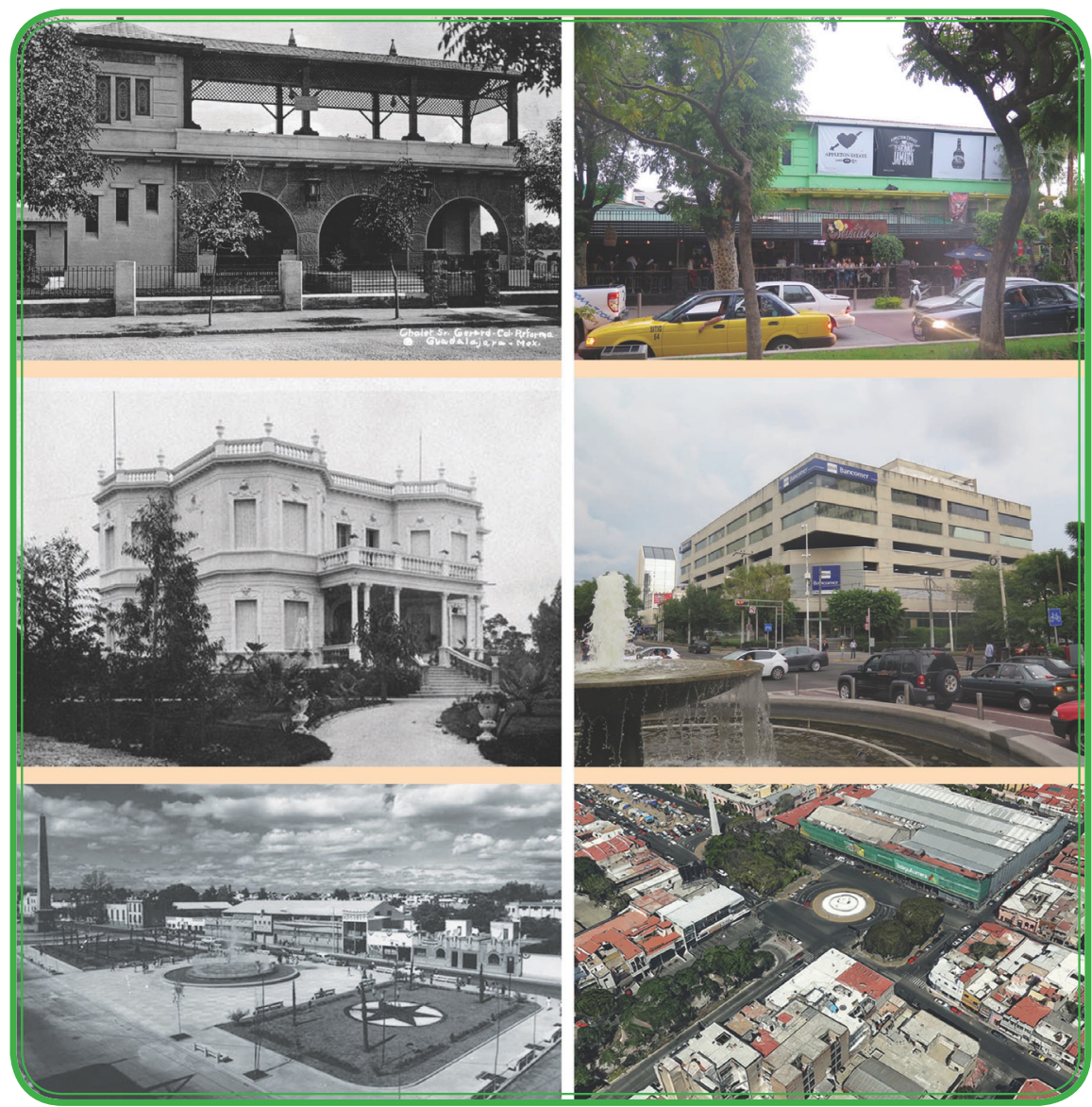

Fotos: Archivo público 2015 (izq. blanco y negro) y elaboración propia (der. color).

servicios necesarios para el desarrollo manufacturero (Rodríguez y Cota, 2006, p. 6).

De manera particular, el modelo exportador impulsó el surgimiento de la industria electrónica, lo que permitió el crecimiento y desarrollo de nuevas centralidades que implicaron la segregación urbana. Lo anterior sienta los antecedentes para la base económica actual que encuentra en los servicios un sector hegemónico para una población creciente de la ciudad, situación que incide directamente en el uso y disposición de ciertas zonas de la misma con condiciones de accesibilidad, movilidad e infraestructura que propicien el mejor desempeño de sus funciones.

Las fotografias anteriores corresponden con algunos de los elementos arquitectónicos ubicados en el área de estudio. En ellas es posible apreciar la transformación que a través de los años han tenido hacia estructuras en las cuales el elemento publicitario se ubica como aspecto relevante, lo que trae consigo una sustitución de la identidad del elemento arquitectóni-

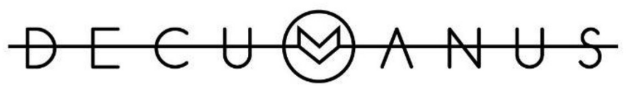

REVISTA INTERDISCIPLINARIA SOBRE ESTUDIOS URBANOS 
co por aquello que representa el signo publicitario.

\section{Perspectiva histórica del fenómeno publicitario en el espacio urbano}

Históricamente se reconoce la aparición del anuncio a la par del nacimiento de los primeros asentamientos humanos, y por consiguiente, de las primeras ciudades en la historia (Leick, 2002). Los individuos requerían de este tipo de instrumentos para intercambiar o comercializar sus productos, buscando en primera instancia la supervivencia.

Este fenómeno, al día de hoy, no ha encontrado límites para incorporarse en prácticamente cualquier tipo de lugar o circunstancia. Si bien se reconoce que no todos los escenarios a través de la historia han sido cómodos o flexibles, la principal particularidad del fenómeno publicitario es su capacidad de adaptación y adecuación sin límite.

En México, "el fenómeno publicitario ve sus primeras manifestaciones en los vendedores de los tianguis en Tenochtitlán, quienes, parados sobre un banco, tenían la intención de publicitar su mercancía" (García Ramírez, p. 29, 2002), sin embargo, es a principios del siglo XX, y gracias a los cambios que acontecieron en la época, cuando nacen nuevas y más efectivas maneras de anunciar los productos existentes, las cuales utilizaban por lo general la entrega personal, en espacios públicos, de artilugios publicitarios para informar sobre la existencia de productos y sus beneficios.
La publicidad en México se limitaba a los gritones, los aparadores de los comercios, algunas agencias de colocación de anuncios y la producción de los mismos a cargo de los periódicos (García Ramírez, 2002, p. 33).

En el texto "Percepción social de la publicidad exterior en la imagen del paisaje urbano" (Maciel, 2013), la autora incorpora citas de autores que mencionan los primeros mecanismos para llevar a cabo campañas publicitarias en el País, los cuales consistían en el uso de vehículos y personas que gritaban los nombres de marcas o productos para darlos a conocer ante audiencias por lo general masivas.

A principios del siglo $\mathrm{XX}$, entonces, destaca ya el grado de intencionalidad del ejercicio publicitario y el de los individuos entendidos como consumidores, quienes eran abordados en la vía pública mediante mensajes que correspondían con las condiciones sociales y culturales propias de la época, "es posible considerar a la Revolución Mexicana como el parteaguas en la actividad publicitaria en el País, trayendo consigo la influencia norteamericana que ha permanecido hasta ahora" (Maciel, 2013, p. 34).

En este sentido, Maciel (2013) describe una serie de sucesos que dejaron en claro la influencia norteamericana en la manera de hacer publicidad en el territorio nacional. Incluso menciona la utilización de artículos novedosos para la época como los tubos de neón, trayendo consigo un cambio en la imagen del paisaje urbano en el territorio ocupado por ciudades con relativa importancia económica, política y social.

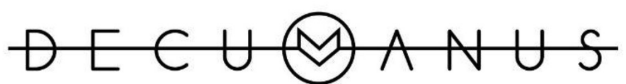

REVISTA INTERDISCIPLINARIA SOBRE ESTUDIOS URBANOS 
En la imagen, que data del año 1959, se aprecia "el anuncio de los que bailan", colocado el 15 agosto de 1957 entre las calles Dionisio Rodríguez y Javier Mina, en Guadalajara, México. Fuente: Maciel (2013).

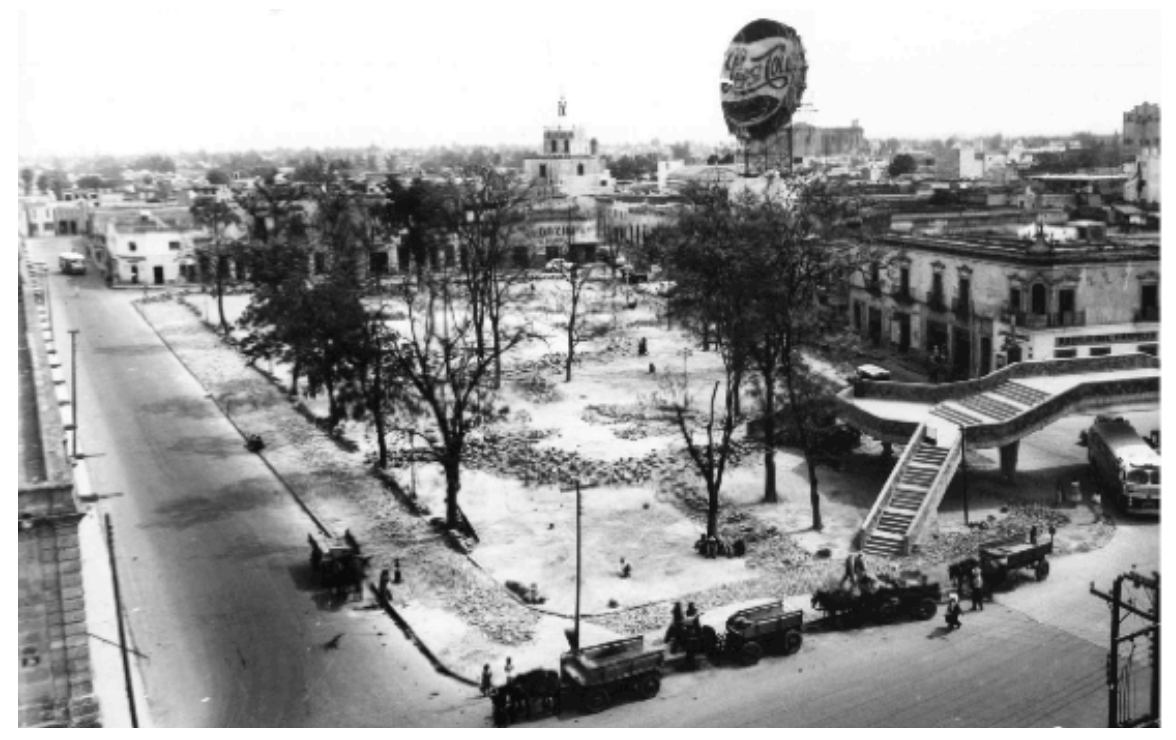

Foto: Archivo público.

El concepto de publicidad exterior empieza a tener sentido a partir de los años 50 cuando se ubican evidencias de soportes publicitarios colocados en estructuras dentro de territorios urbanos.

En el caso particular de Guadalajara, esta época, la de los años 50, se considera como una en la que el fenómeno de la publicidad exterior se expandía, e incluso para la colocación de los anuncios "cualquier espacio era aprovechable de las principales avenidas y calles, sin embargo, uno de ellos aventajó en cuanto a tamaño y diseño, que en su momento vino a representar y a dar identidad a un barrio o zona de la ciudad". Este anuncio publicitaba una marca de refresco (Maciel citando a Ramos López, 2008, p. 11).
La colocación de este primer anuncio, conocido por la población como el anuncio de los que bailan, en el entorno urbano de la ciudad de Guadalajara generó un interesante rechazo social que es mencionado en el trabajo de la autora:

[...] realmente el anuncio altera notablemente el ornato de la zona y sí sería aconsejable su cambio desde luego, para darle el realce que se merece el Mercado Libertad, cuya construcción arquitectónica debe ser cuidadosamente vigilada por todos los ciudadanos de Guadalajara (Maciel, citando a Ramos López, 2008, p. 12).

La cita anterior resulta interesante, pues, aunque expresa una parte de la opinión pública, esto no fue suficiente para detener la incorporación de

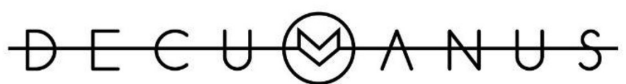

REVISTA INTERDISCIPLINARIA SOBRE ESTUDIOS URBANOS 
esta práctica publicitaria como parte del paisaje urbano de la época, situación que a la fecha sigue estando presente. En el documento antes citado (Maciel, 2013), se incorpora una serie de fotografías que son evidencia de la manera en que el espacio urbano iba siendo sometido al criterio mercantil, lo que permite inferir sobre la naturaleza de poder que a través de los años se ha ido consolidando, de tal manera que hoy en día sigue teniendo capacidad para incidir, incluso, en el incumplimiento de las normas de control urbano.

Al revisar el Reglamento de Anuncios para el Municipio de Guadalajara (2015), ${ }^{4}$ en el texto que corresponde al Artículo 2 que señala las disposiciones de orden y observancia y que tienen como objeto (apartado IV): Regular la fijación, instalación, conservación, ubicación, distribución, exhibición, emisión, características y requisitos de anuncios en los sitios o lugares a los que tenga acceso el público o que sean visibles o audibles desde la vía pública, para lo cual se establecen los siguientes lineamientos: a) Asegurar que los anuncios producidos para la publicidad de negocios, locales comerciales, productos y demás actividades económicas y sociales, sean planeados, dosificados, diseñados y ubicados en la forma y en los sitios dispuestos y que no representen daño alguno a la población, ni atenten contra la identidad y los elementos esenciales de la composición, como son el equilibrio, la claridad, el orden y la estética que guarda cada espacio territorial del municipio.

4 http://transparencia.guadalajara.gob.mx/sites/ default/files/reglamentos/Reg.AnunciosGdl_0.pdf
A este respecto, es sencillo identificar el incumplimiento de la norma para una gran cantidad de anuncios publicitarios en el área de la ciudad de Guadalajara y su Zona Metropolitana, situación que obliga a la reflexión sobre las implicaciones que esto ha tenido en el orden, identidad, equilibrio, estética y valor simbólico del entorno urbano actual.

\section{La omnipresencia publicitaria}

La ciudad, comunidad de convivencia, encuentra su origen en la naturaleza social del ser humano y esa dimensión social es pareja del fenómeno comunicativo. La comunicación está indiscutiblemente ligada a lo social, por lo que hablar de ciudad es inevitablemente hablar de comunicación (Baladrón, 2007, p. 75).

La comunicación es un proceso que evidentemente requiere del otro para su cumplimiento, es decir, sin un receptor que genere retroalimentación con el emisor, el proceso no existe, es limitado, solo informa. Esto proceso de ida y vuelta, representa uno de los fenómenos más relevantes del escenario urbano contemporáneo donde prevalece la idea de estar comunicado como la mejor forma de estar vigente.

Los procesos de comunicación repercuten de manera directa entre quienes conforman algún tipo de auditorio en el cual se emite un mensaje en particular. La interacción que de este procedimiento resulte, determinará en gran medida la forma de actuar y entender las cosas por parte de quienes recibieron estos mensajes, los cuales, se encuentran sujetos

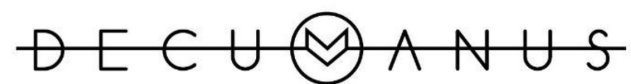

REVISTA INTERDISCIPLINARIA SOBRE ESTUDIOS URBANOS 
a iguales procedimientos de interpretación para verificar el interés en los mismos.

A este respecto, la comunicación está ciertamente sometida a varios aspectos a considerar: las particularidades de quien emite el mensaje, su intención, los canales que utiliza para tal efecto, los códigos y las expresiones que permiten su interpretación, las especificaciones de la audiencia, sus creencias, sus valores, deseos y necesidades. Igual importancia tienen las condiciones del contexto donde se desarrolla este proceso de comunicación, en el cual los factores económico, social y político resultan como determinantes a partir de una visión contemporánea que reconoce la correlación existente entre todos los elementos antes mencionados como parte fundamental de la comunicación actual. Diversos autores coinciden en señalar que "la comunicación, para el caso de las ciudades, tiene entre sus fines la socialización, es decir, la integración social" (Baladrón, 2007, p. 76).

La socialización que implica la comunicación no excluye en absoluto la afirmación de la individualidad; precisamente la necesidad de expresar esta última es, de hecho, lo que está en la base de la ineludible comunicación. De este modo, el escenario urbano se ha convertido hoy en día en un claro ejemplo de expresión de las más diversas identidades, no solo grupales sino individuales (Baladrón, 2007, p. 76).

Este tipo de expresiones han asumido una forma visual que les ha permitido posicionarse en los diferentes escenarios de lo que hoy entendemos como ciudad.

Que la comunicación contribuya a la integración social por incrementar nuestro conocimiento de lo propio y lo ajeno significa que ilumina la realidad, la pone en primer plano, la hace evidente a los ojos para que sea interpretada, para darle significado (Baladrón, 2007, p. 77).

Esta particularidad del fenómeno visual, en el cual se proporcionan estímulos visuales a un determinado tipo de individuos, es lo que en parte permite a la publicidad tener una forma omnipresente, pues cualquier rincón o escenario puede adquirir una función de soporte ante la inminente presencia publicitaria. Esta situación que bien puede ser parte de un debate crítico sobre dicha postura, también permite reconocer en la publicidad una conjugación entre tres conceptos que conforman nuestra realidad: la publicidad como tal; la ciudad que puede asumir una especie de soporte, y el consumo como actividad, sin la cual, el modelo económico vigente no tendría sentido.

"La historia de la ciudad está ligada a la historia de las ciudades" (Baladrón, 2007, p. 78), lo que marca una relación constante y duradera sin la cual uno y otro no serían lo que hoy son. La particularidad de llamar la atención, un atributo de la publicidad, obedece a una intencionalidad por parte del emisor para comunicar una serie de discursos persuasivos que encuentran en el fenómeno visual la herramienta necesaria para captar la atención de un ciudadano que se mueve y se de-

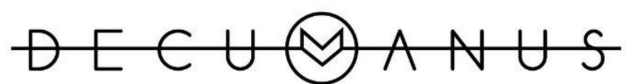

REVISTA INTERDISCIPLINARIA SOBRE ESTUDIOS URBANOS
Núm. 2. Vol. 2. Octubre 2016-Octubre 2017. Instituto de Arquitectura, Diseño y Arte.

Universidad Autónoma de Ciudad Juárez. ISSN: 2448-900X 
sarrolla en diferentes escenarios propios de la ciudad. Por su estructura:

La ciudad se convierte en teatro publicitario, un desfile de mensajes comerciales y marcas, un devenir de persuasión al servicio de intereses de la nueva economía y de los sectores sociales más pujantes de la sociedad. Símbolo de la modernidad, la ciudad es tomada por la publicidad (Baladrón, 2007, p. 80).

A este respecto habrá que señalar que el consumo de productos y servicios que demanda una población en particular requiere de la implementación de soportes para la emisión de mensajes publicitarios. Esto proporciona una idea básica sobre la cual podemos entender el alcance del fenómeno publicitario como un aspecto que avasalla el orden y las circunstancias existentes para la funcionalización de las cosas en sentido comercial.

El consumo y el consumismo como tales se convierten en los factores detonantes, no solo de la publicidad en la ciudad, sino de las diferentes formas y dimensiones que esta última adquiere para el cumplimiento de objetivos relacionados con estrategias comerciales ligadas al marketing como disciplina mediante la cual se intenta satisfacer las necesidades y los deseos de individuos en general.

La modernidad sugiere y provoca un amplio abanico de conductas individuales y colectivas de consumo que invaden la vida cotidiana. La ciudad, como poderoso y fascinante escenario de consumo, adop- ta una imagen dinámica, colorista y placentera, en la que la burguesía urbana intenta expresar el prestigio alcanzado (Baladrón, 2007, p. 80).

La implementación de escenarios para la proliferación del consumo mediante la escenificación de ambientes convertidos en estimuladores de sentidos forma parte sustancial de los modernos escenarios urbanos. En estos lugares de la ciudad se procura el consumo en el individuo con el fin de incorporarse a un determinado grupo social con ciertas características que lo hacen parecer un modelo a seguir. En estos mismos lugares, la publicidad es la encargada de emitir signos y símbolos cuya interpretación está debidamente planeada, es decir, intencionada.

La omnipresencia de la publicidad no se limita a la naturaleza de los espacios, si es necesario los trastoca, los envuelve y los convierte en espacios de promoción y para el consumo. "A partir de la segunda mitad del siglo XIX se descubre la importancia de la calle como canal comunicativo, y entonces nace la publicidad exterior como medio publicitario" (Baladrón, 2007, p. 83), lo que significa el inicio de un nuevo modo para expandir los alcances de la publicidad hacia el lugar donde los individuos se encuentran. La atención visual es por lo tanto, el principal objetivo de persuasión, en el cual no existen limitantes que no puedan ser sorteados mediante artilugios de diverso orden.

El fenómeno publicitario, por lo tanto, actúa de modo particularmente diferente:

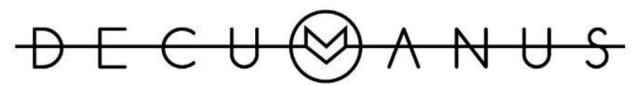

REVISTA INTERDISCIPLINARIA SOBRE ESTUDIOS URBANOS 
Salvando las evidentes diferencias, la publicidad comparte dos de los atributos que los antiguos catecismos atribuían a Dios: es persuasiva y ubicua. Persuasiva en el sentido que define el acreditado Webster's Dictionary: abunda y se difunde por todas partes. Ubicua por que está presente a un mismo tiempo en todo lugar (Aprile, 2000) (Baladrón, 2007, p. 86).

Lo que también es necesario rescatar es que la publicidad ciertamente cumple una variedad importante de funciones. Una de ellas es servir de soporte estratégico mediante el cual muchas de las empresas existentes puedan seguir funcionando.

En un mundo donde la imagen se ha convertido en la forma mediante la cual entendemos todo lo que nos rodea, el fenómeno publicitario se sitúa como el artilugio capaz de crear, modificar y estructurar imágenes en la mente de los ciudadanos bajo un esquema de intencionalidad en el cual subyace el criterio mercantil y de consumo.

Para sobrevivir, el individuo requiere de la cooperación y equilibrio de dos sistemas: uno por medio del cual recibe los estímulos del exterior, y el otro por medio del cual responde a esos estímulos (González, 2007, p. 135).

En relación con lo anterior, el autor expresa la existencia de un tercer sistema que resulta fundamental para el conocimiento interno y externo del ser humano: el sistema simbólico, cuyo argumento se centra en el papel que juega el enorme conjunto de sím- bolos que existe en la actualidad y la enorme carga de significado que está dispuesta para ser interpretada y significada. Como analogía de lo anterior, se sugiere hacer un recorrido mental del área geográfica o área de estudio del presente proyecto de investigación para percatarse de la notable proliferación de elementos dispuestos en cualquier espacio posible, listos para ser identificados y dispuestos para comunicar algo.

Quienes transitan por este tipo de espacios urbanos, en realidad no siempre tienen un contacto directo con las cosas u objetos. La interpretación que llevan a cabo del entorno, se genera a partir de hechos concretos como la identidad, los sentimientos, las sensaciones, las experiencias y el intercambio. Estas manifestaciones son por lo general promovidas por elementos ligados con la actividad comercial y política. Esto no sugiere que el factor social sea inexistente, sin embargo, a diferencia del resto, es notoriamente desigual.

La enorme cantidad de elementos publicitarios existentes en la zona comercial de Chapultepec, emiten constantemente fuertes cargas de significado a la totalidad de individuos identificados como consumidores. Pero los signos y símbolos que el fenómeno emite, no corresponden con la realidad como tal, por el contrario, contribuyen con el imaginario de las personas que traen consigo un andamiaje de conceptos y contenidos que le permiten formar su propia idea de la vida cotidiana, es decir, de las representaciones.

En el espacio urbano contemporáneo, y gracias a la importante presen-

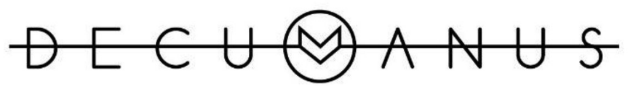

REVISTA INTERDISCIPLINARIA SOBRE ESTUDIOS URBANOS
Núm. 2. Vol. 2. Octubre 2016-Octubre 2017. Instituto de Arquitectura, Diseño y Arte.

Universidad Autónoma de Ciudad Juárez. ISSN: 2448-900X 


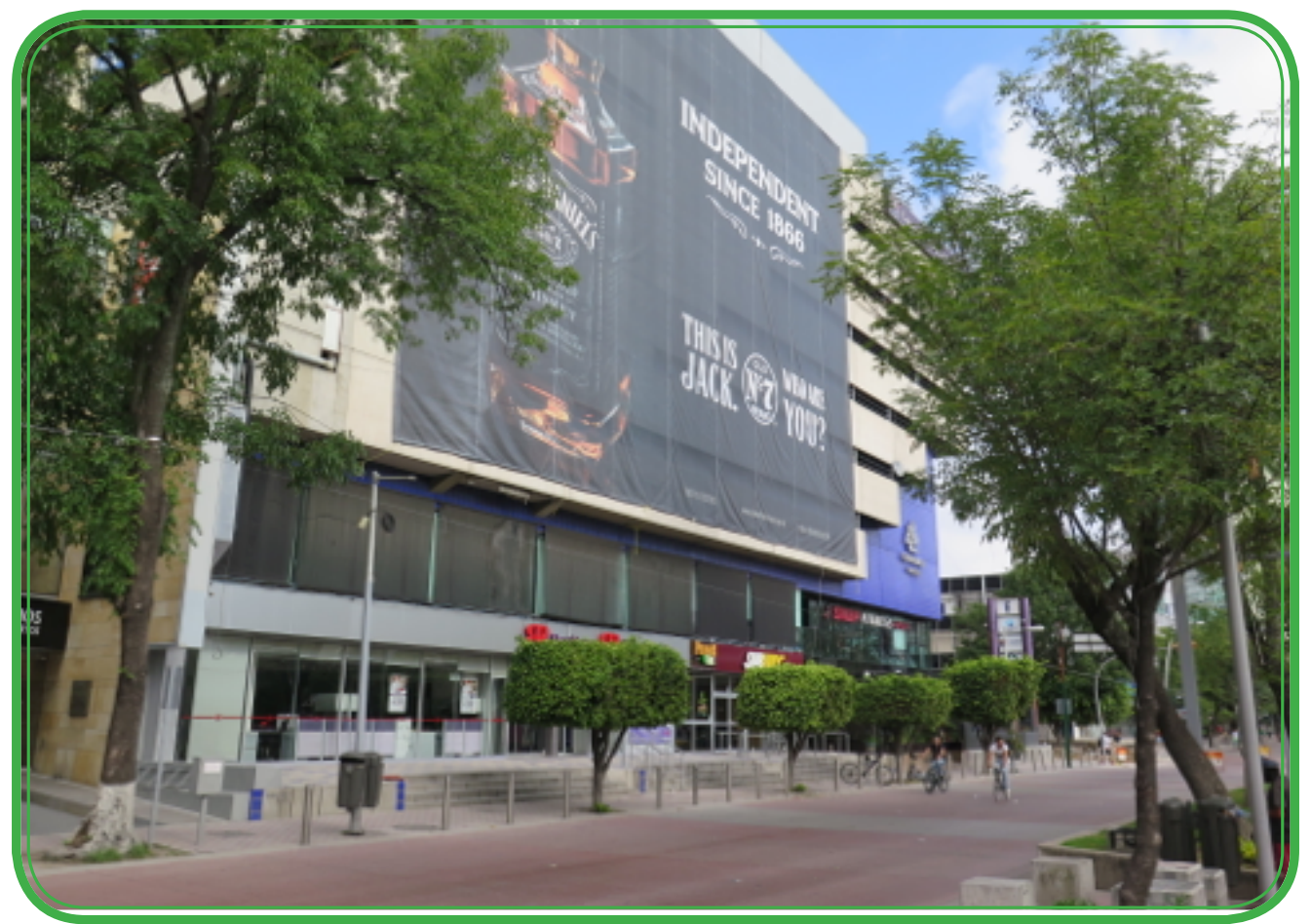

Foto: Elaboración propia 2015.

cia del fenómeno publicitario, grupos sociales identificados como segmentos de mercado, construyen su realidad a través de imágenes, mensajes y modelos de conducta que son promovidos como la única opción de ser y estar.

En el área de estudio, es evidente la utilización de cualquier espacio posible para la transmisión de ideas sobre marcas o productos en los que subyace un grado de intencionalidad estratégica en función del análisis de las particularidades conductuales de quienes asisten con regularidad a este tipo de escenarios urbanos.

Cuando el individuo transita por espacios urbanos dispuestos de esta manera, el significado del lugar encuentra mayor argumento referencial a partir de la imagen comercial que en él exis- te, que aquella que le corresponde arquitectónica e históricamente.

En este punto, el fenómeno publicitario es considerado como un sistema simbólico que contribuye al proceso cultural del individuo, particularmente en relación con su entorno, el cual, a partir del desarrollo económico de la sociedad, ocupa un lugar cada vez más relevante en el escenario contemporáneo.

Por tanto, un primer acercamiento al concepto de cultura sería definirlo como un conjunto organizado de sistemas de signos y símbolos, un sistema de sistemas (González, 2007, p. 140).

La zona comercial de Chapultepec en su conjunto, y particularmente en el área con mayor presencia comer-

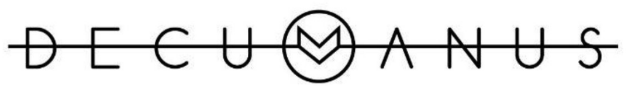

REVISTA INTERDISCIPLINARIA SOBRE ESTUDIOS URBANOS 
cial, es un lugar que demuestra, mediante su oferta, la materialización de nuevas centralidades cuya principal característica es propiciar la obtención de cualquier necesidad (contemporánea) en un solo lugar. Con ello, el ciudadano cuenta con la opción de complementar su actuar a partir de su forma de ser y estar.

\section{Hallazgos}

La zona comercial de Chapultepec, ubicada en la ciudad de Guadalajara, México, es claramente un espacio interconectado. Dicha conexión no solo corresponde con los aspectos físicos del lugar, los cuales, por cierto, permiten a individuos o transeúntes ir de un lugar a otro a partir del interés que éstos tengan en función de aquello que perciben, que los persuade y los motiva.

La conexión a la que se refiere este apartado inicial va más allá de los aspectos tangibles. El concepto implica un estado en el que se conjugan diversos escenarios creados y modificados desde una perspectiva mercantil que busca satisfacer las necesidades de los individuos entendidos como consumidores.

Si bien la zona en cuestión ha sufrido importantes cambios, lo que hoy prevalece son dos tendencias de modificación del estado físico claramente observables: la primera de ellas consiste en la adecuación de varios de sus elementos arquitectónicos (principalmente los cercanos a la avenida Chapultepec), hacia una economía basada en los servicios, el esparcimiento y la socialización. La segunda corresponde con la utilización de una importante cantidad de superficie para la colocación de instrumentos publicitarios.

Este conjunto de situaciones integra y constituye una vocación que trasciende por encima de sus particularidades históricas y de identidad del lugar. El modelo de espacio urbano contemporáneo que se asocia con la zona de Chapultepec en Guadalajara, es aquel que cumple una serie de funciones:

- Es un espacio público al que puede acceder cualquier persona sin restricción.

- Es un lugar de la ciudad al que es posible acudir para cubrir necesidades de pago de servicios de uso cotidiano.

- Es un lugar al que se acude para pasar un rato con los amigos, para tener una velada agradable y consumir bebidas alcohólicas.

- Es un lugar en el que es posible realizar negocios de diversa índole.

- Es un lugar de la ciudad que promueve la práctica del ocio, del esparcimiento. Un lugar para ir a comer, recorrer en bicicleta o simplemente caminar.

Esta condición evidentemente requiere de la adecuación de los espacios en función de las nuevas tendencias de comportamiento de los ciudadanos entendidos como consumidores, quienes se identifican con el sitio a partir de lo que en él acontece y por la presencia de marcas o productos que se comercializan en la zona.

Durante el ejercicio de la presente investigación, se documentó la existencia de varios grupos sociales, los cuales se apropiaban de ciertas áreas

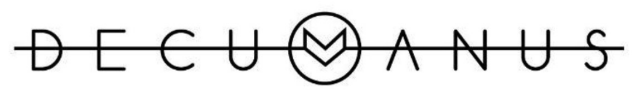

REVISTA INTERDISCIPLINARIA SOBRE ESTUDIOS URBANOS 
de la zona para manifestarse y con ello, expresarse y mantener su condición respecto a los demás. Lo anterior sugiere que el sentido estricto del espacio público prevalece en la parte esencial, sin embargo, en esta nueva configuración del entorno urbano se muestran importantes evidencias que obligan al análisis respecto a las implicaciones que esto ha tenido en la identidad del lugar, su historia y el individuo que transita por el lugar.

Para lograr comprender el fenómeno y generar congruencia con la metodología de trabajo, se procedió a la realización de tres herramientas importantes para la investigación: la realización de encuestas directas a personas que transitan por el lugar de estudio, la encuesta en redes sociales y el levantamiento de negocios existentes en la zona.

En la parte que corresponde con la aplicación de una encuesta que permitiera aproximarnos a la descripción del transeúnte del lugar, se aplicaron 30 encuestas directas a individuos de manea aleatoria que durante el mes de noviembre de 2015, se abordaron en el área de estudio.

\section{Resultados:}

- Los rangos de edad que más presencia tienen en la zona son los comprendidos entre los 15 y 21 años.

- La mayoría de los encuestados resultaron ser estudiantes de nivel licenciatura (83.3 \%).

- El género que más presencia tiene en la zona es el masculino (56.66 $\%)$, mientras que las mujeres re-

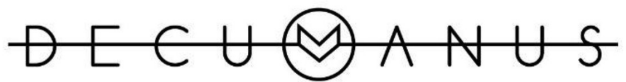

REVISTA INTERDISCIPLINARIA SOBRE ESTUDIOS URBANOS presentan el $43.33 \%$ de la población.

- Los usuarios manifestaron visitar la zona de manera ocasional en un $46.66 \%$, mientras que solo el 26.66 $\%$ expresó hacerlo en fines de semana.

- La estadística destaca que este espacio urbano de la ciudad es un lugar de reunión de amigos (70 \%) principalmente.

- Respecto a las empresas que mayor presencia tienen en la zona de estudio, destaca la empresa Starbucks con 11 menciones, seguida por la tienda de conveniencia Oxxo con 5 menciones como su primera opción de respuesta.

- Sin embargo, la mayoría de los encuestados (66.66 \%) considera que la cantidad de negocios es mucha, y que sus precios oscilan entre ni caros ni económicos y medianamente caros (46.66 \%), resultado congruente cuando se cruza con la opinión sobre el costo de acudir a la zona de Chapultepec que es, en promedio, regular (76.66 \%).

- Los encuestados consideran que el valor en general de la zona es alto (56.66 \%).

- El gasto promedio que más ocurre entre este grupo focal es una cantidad entre 100 y 200 pesos (60 $\%)$, sin embargo, un $20 \%$ de esta población menciona tener un gasto promedio entre 200 y 300 pesos, cantidad que puede ser contrastada con el ingreso promedio de la población en Zona Metropolitana.

A la par del ejercicio anterior, se realizó una encuesta por redes sociales. El resultado fue el siguiente: 
encuestas realizadas, 160:

- Del total de personas que contestaron el instrumento, el 58 \% fueron mujeres y $42 \%$ hombres.

- De ese universo de respuestas, el $75 \%$ mencionó ser estudiante de nivel licenciatura, $18 \%$ de maestría y un $6 \%$ de doctorado.

A continuación, se muestra la diversidad de ocupaciones de los individuos que contestaron la encuesta. A este respecto, el estudio indica una diferencia interesante del que es estudiante, seguida de quién se emplea como contador (19), diseñador (18) y empresario (16).

- En lo que respecta a la frecuencia con la cual visitan el área de estudio, el 77 \% mencionó hacerlo de manera ocasional (119); el 14 \% (21) en fines de semana, y el $9 \%$ (14) dos o tres veces por semana.

- $\quad$ El 44 \% de los encuestados mencionó que son los amigos las personas con las cuales se acompañan durante la visita del área en cuestión. Para el $32 \%$ de las respuestas, la familia es el principal acompañante.

- Cuando a las personas se les preguntó sobre las empresas que más presencia tienen en la zona, el resultado mostró cierto equilibrio entre las organizaciones comerciales, sin embargo, empresas como Telcel, Librerías Gandhi, las cafeterías Starbucks y La Estación de Lulio, los restaurantes Wings Army y Chai, resultaron como los de mayor reconocimiento por parte de los individuos en la zona de estudio.
- A este respecto, la cantidad de empresas existentes en el área de trabajo es mucha, para un 68 \% (105) de los encuestados. Así mismo, el $52 \%$ (81) considera que acudir a la zona es medianamente caro, situación que se contrasta cuando se les pregunta sobre el precio particular de los productos en la zona, el cual es considerado como regular por el $75 \%$ (119) de los encuestados.

- El valor económico estimado de la zona en su conjunto es percibido como medio por el 53 \% (83) de encuestados.

- Cuando se cuestiona sobre la cantidad de dinero que en promedio se gasta al visitar la zona, el resultado establece que el 50 \% (63) de las personas gasta entre 200 y 300 pesos, dejando en segundo lugar a quienes invierten más de 400 pesos $(26 \%)$ cada vez que visitan el lugar.

Cuando a las personas participantes de este instrumento se les cuestionó sobre qué tipo de productos son, a su criterio, los que más se venden en la zona, una cantidad mayoritaria mencionó tres categorías de productos: bebidas alcohólicas, cervezas y comida.

- El rango de edad que más presencia tiene en la zona es el que se ubica entre los 19 y 25 años (64\%), seguido por quienes tienen entre 25 y 45 años de edad (36\%).

- Este grupo de individuos menciona en un $49 \%$ (78), que distraerse es la principal razón para visitar la zona.

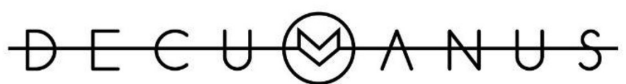

REVISTA INTERDISCIPLINARIA SOBRE ESTUDIOS URBANOS
Núm. 2. Vol. 2. Octubre 2016-Octubre 2017. Instituto de Arquitectura, Diseño y Arte.

Universidad Autónoma de Ciudad Juárez. ISSN: 2448-900X 
- Un 30 \% (48) mencionó que pasarla con los amigos es su principal razón de visita al lugar. El 73 \% (117) expresó que cuando visita la zona acude por lo general a los mismos lugares y solo el $26 \%$ mencionó otros lugares del área.

- Cuando a los encuestados se les preguntó su opinión con respecto a que los edificios en la zona sean utilizados como soportes publicitarios, el $34 \%$ (54) dijo estar en desacuerdo, y el $31 \%$ (48), en total desacuerdo. Llama la atención que un $19 \%$ (30) estuvo de acuerdo con esta práctica, y que un 16 \% (25) se mostró indeciso.

- Vinculado con lo anterior, el 54 \% (77), considera que es mucha la cantidad de anuncios publicitarios en la zona, y el 43 \% (61), mencionó como regular la presencia publicitaria.

- Cuando se les pregunta si la publicidad tiene la capacidad de modificar la conducta de las personas, el $58 \%$ (83) consideró estar de acuerdo, y el $18 \%$ (26) dijo estar totalmente de acuerdo.

- Los colores que más están posicionados en la mente de las personas encuestadas, cuando se les pide recordar la zona, son el verde (44), el rojo (27) y el azul (18).

\section{Levantamiento de negocios existentes en la zona de estudio}

La realización de este instrumento se concreto en el mes de octubre de 2015. Su desarrollo permitió identificar siete categorías de negocios existentes en la zona de estudio, lo que arroja una cantidad importante de informa- ción para identificar una transformación de uso del área de estudio que evidentemente repercute en la configuración de otros espacios que se vinculan de manera directa o indirecta. La existencia de 441 locales dedicados a prestar servicios profesionales, permite dimensionar la nueva vocación del lugar y el papel que el fenómeno publicitario tiene en todo ello.

A continuación se presenta el desglose del levantamiento, incluyendo las categorías identificadas y los porcentajes que resultaron por la aplicación del instrumento:

\begin{tabular}{|c|c|c|}
\hline \multicolumn{3}{|c|}{$\begin{array}{l}\text { NEGOCIOS EXISTENTES EN LA ZONA COMERCIAL } \\
\text { DEL ÁREA DE ESTUDIO }\end{array}$} \\
\hline UNIVERSO & CATEGORÍA & PORCENTAJE \\
\hline \multirow{8}{*}{441} & $\begin{array}{l}\text { Oficinas de gobi- } \\
\text { erno. }\end{array}$ & $1.36 \%$ \\
\hline & $\begin{array}{l}\text { Establecimientos } \\
\text { de ropa y acceso- } \\
\text { rios }\end{array}$ & $7.02 \%$ \\
\hline & Restaurantes-bar & $10.88 \%$ \\
\hline & $\begin{array}{l}\text { Restaurantes, cafe- } \\
\text { terías y panad- } \\
\text { erías. }\end{array}$ & $20.63 \%$ \\
\hline & $\begin{array}{l}\text { Oficinas de servi- } \\
\text { cios profesionales. }\end{array}$ & $52.15 \%$ \\
\hline & No especificados. & $1.81 \%$ \\
\hline & Locales vacíos. & $6.12 \% \%$ \\
\hline & Total & $99.97 \%$ \\
\hline
\end{tabular}

Estos datos no solo demuestran la notable presencia de negocios que ofrecen servicios profesionales, lo cual corresponde con la vocación económica del lugar y que se vincula con el desarrollo tecnológico que al mismo tiempo requiere de áreas de conocimiento específicas que permiten la satisfacción de necesidades de otras organizaciones comerciales de igual o mayor tamaño. Un aspecto relevante

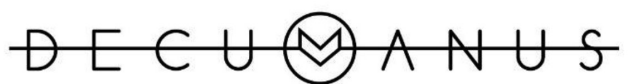

REVISTA INTERDISCIPLINARIA SOBRE ESTUDIOS URBANOS 


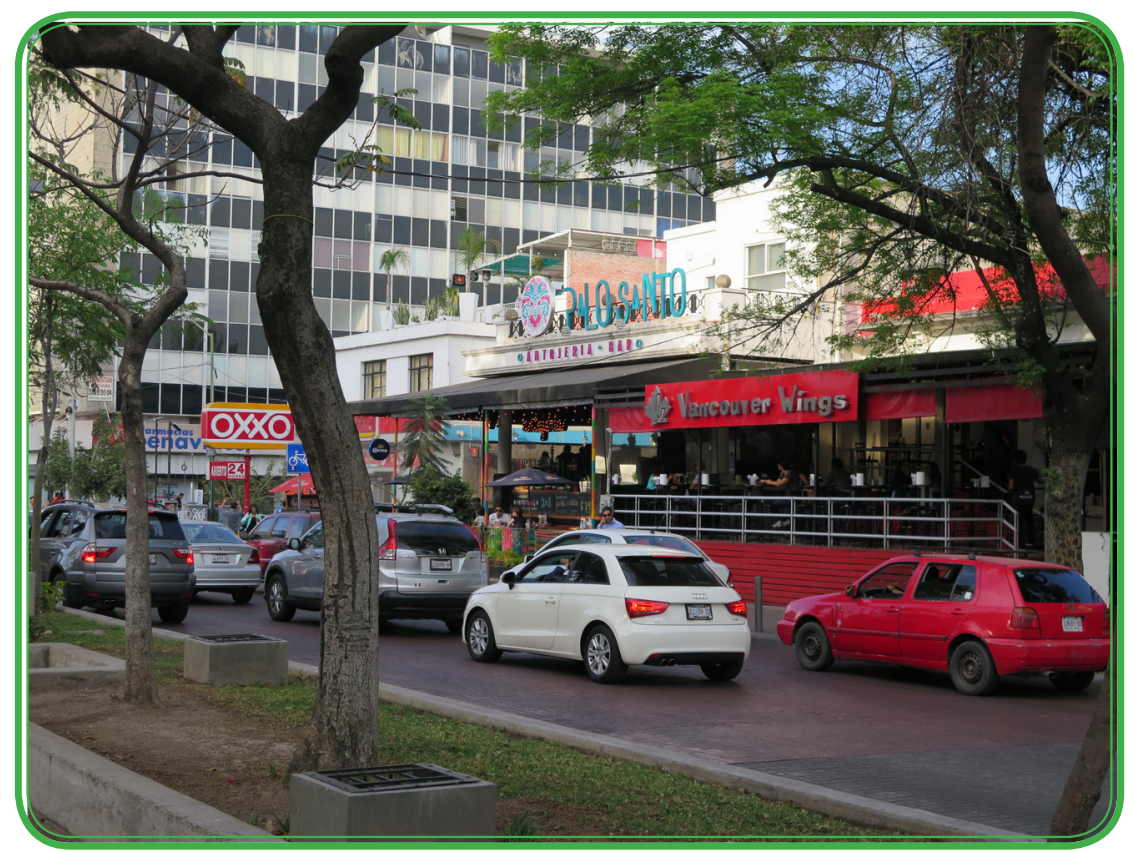

Foto: Elaboración propia, registrada durante el mes de noviembre de 2015.

en este apartado es la evidencia de un proceso de promoción de servicios que utiliza principalmente a los medios digitales para comunicar sus cualidades como argumento publicitario, destacando la ubicación como eje estratégico.

Un caso particular es el negocio denominado Fastoffice, el cual ofrece renta de espacios físicos para el desarrollo de negocios. En su sitio web (http://www.fastoffice.mx), es posible detectar la importancia que le otorgan a la ubicación geográfica de sus oficinas. Esta condición, que es un dato de referencia geográfica, resulta de vital importancia para un creciente número de negocios que encuentran en el networking (entendido como forma de producción) su área de especialización ideal para la creación de proyectos de negocio.

Otro aspecto relevante de este dato es que permite reconocer la importancia que va adquiriendo la necesi- dad que tienen las empresas y los corporativos para adecuar sus oficinas a partir de las nuevas formas de hacer negocio, situación que sirve de argumento para modificar los aspectos fisicos del lugar y de la zona en que se encuentran ubicados. Si bien es cierto que este es un solo caso, cuando se detecta que un $52.15 \%$ de negocios existentes en la zona está compuesto por oficinas de servicios profesionales, entonces es posible inferir sobre las dimensiones que este hecho provoca en la zona urbana que concentra estas circunstancias.

En este caso particular, la utilización del discurso publicitario tiene por lo general pequeñas dimensiones, sin embargo, el problema se genera mediante la acumulación de casos que terminan por incidir en la configuración del espacio urbano en que dichos negocios o empresas tienen presencia. Aquí, como en otros casos, vale la pena mencionar que las regulaciones

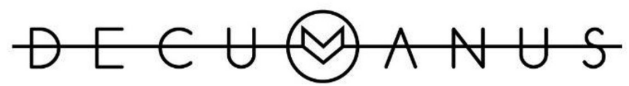

REVISTA INTERDISCIPLINARIA SOBRE ESTUDIOS URBANOS 


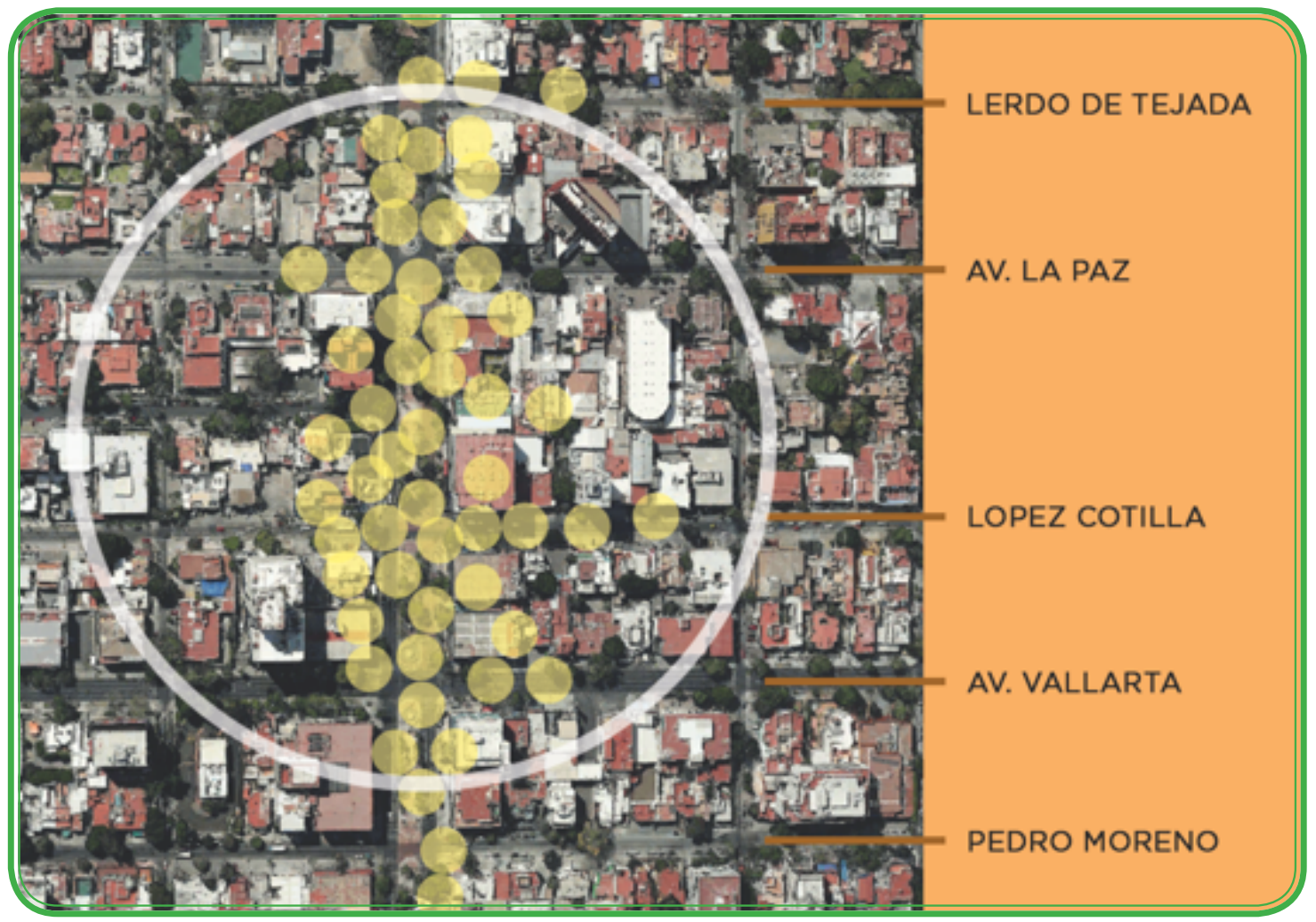

Fuente: Elaboración propia, con imagen de Google Earth, 2016.

establecidas desde el Municipio operan de manera limitada permitiéndole a las organizaciones comerciales o personas, cierta libertad de operación para la disposición de anuncios por encima de lo que establece el reglamento municipal. ${ }^{5}$

En la imagen anterior, se muestra un ejemplo de lo que acontece en el área de estudio, en cuanto a la colocación de elementos publicitarios; así, es posible observar el impacto que tiene la desregulación del anuncio en el espacio urbano. Este evidente incumplimiento de la norma propicia que cada organización o individuo coloque anuncios de cualquier tamaño y material, sin considerar el impacto

$5 \quad$ Reglamento de Anuncios para el Municipio de Guadalajara.

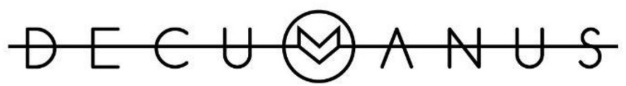

REVISTA INTERDISCIPLINARIA SOBRE ESTUDIOS URBANOS que éstos tienen en el entorno inmediato, y mucho menos en el contexto en general.

Otro dato resultante de este instrumento es la ubicación geográfica de la mayor concentración de actividades comerciales de la zona de estudio. A este respecto, destaca el área comprendida por los cruces de las calles Lerdo de Tejada, Avenida La Paz, López Cotilla, Avenida Vallarta y Pedro Moreno con la Avenida Chapultepec, como lo muestra la imagen siguiente:

Esta acumulación de negocios ciertamente conserva la cuadrícula que dio origen a la traza de las calles de la ciudad (López Moreno, 2001), sin embargo, teniendo como argumento la necesidad de comunicar las particularidades que definen a los negocios existentes, la modificación de espa- 


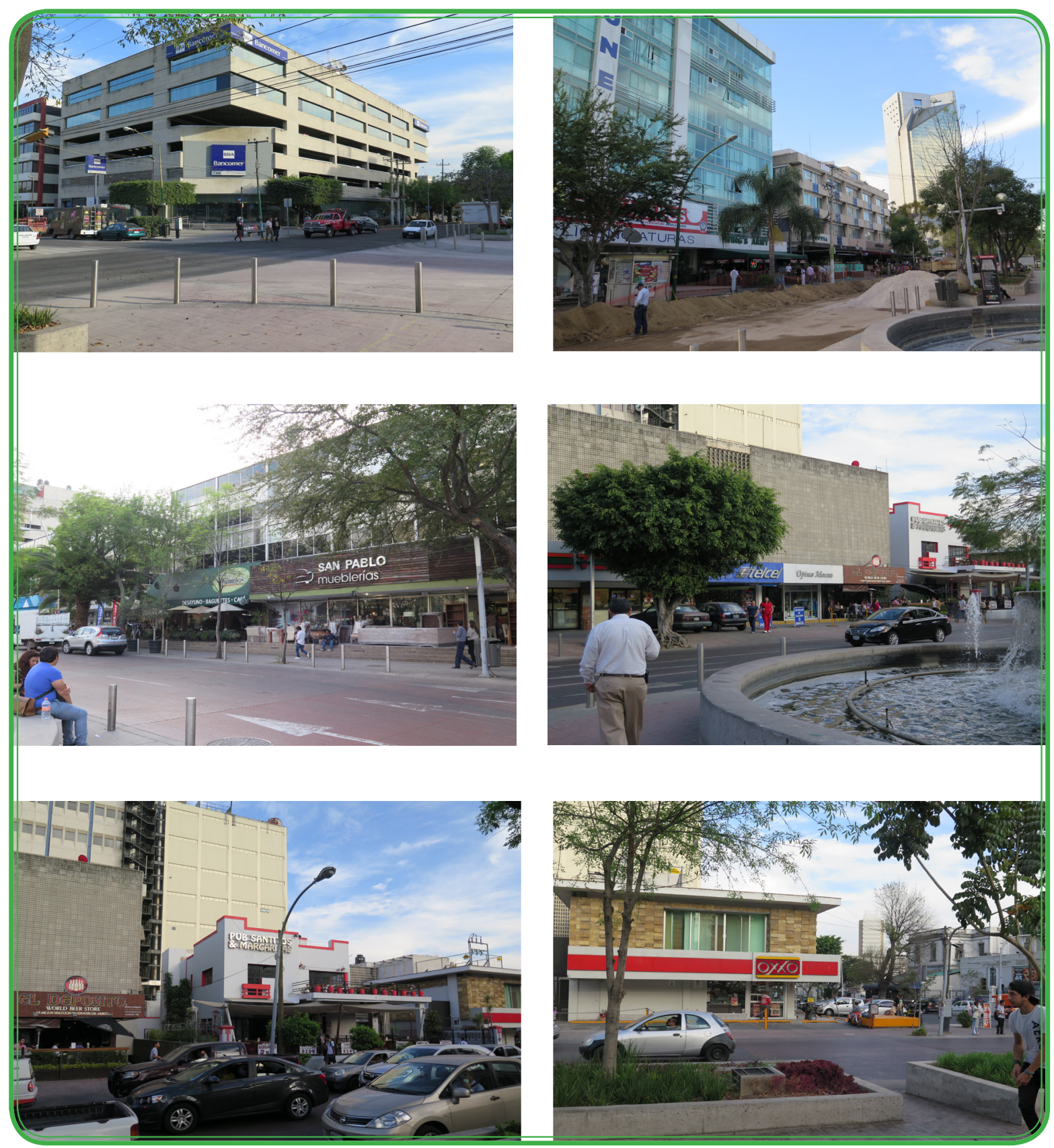

Fotos: Elaboración propia durante el mes de septiembre de 2015.

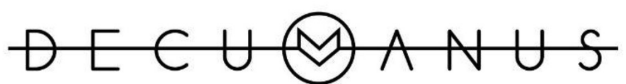

REVISTA INTERDISCIPLINARIA SOBRE ESTUDIOS URBANOS
Núm. 2. Vol. 2. Octubre 2016-Octubre 2017.

Instituto de Arquitectura, Diseño y Arte.

Universidad Autónoma de Ciudad Juárez. ISSN: 2448-900X 
cios externos e internos de negocios para convertirse en soportes publicitarios, es la constante.

En relación con lo antes mencionado, en esta secuencia de imágenes de los locales comerciales ubicados en algunos de los principales cruces de calles y avenidas del área de estudio, se observan ejemplos de apropiación del espacio físico para la colocación de anuncios publicitarios.

\section{Conclusiones}

El fenómeno publicitario ha logrado constituirse como el punto de referencia espacial y atemporal de los lugares más representativos de la zona de estudio. Lo anterior no solo describe la importancia del fenómeno entre la población en general, también pone en evidencia una tendencia del individuo hacia lo inmaterial y a la perturbación continua de las cosas, de modo que su actuar está en función de aquello que percibe y que no necesariamente corresponde con la realidad concreta, sino con aquella que se impone como parte de una estrategia que busca y promueve el consumismo como condición humana, lo que genera al mismo tiempo, la acumulación de recursos económicos para pequeños sectores empresariales. - El sistema simbólico que permite el entendimiento y la comprensión de la realidad cotidiana de los individuos se encuentra atiborrado de elementos publicitarios, todos dispuestos a partir de las nuevas tendencias de estilos de vida de la población, las cuales modifican las formas de ser, vivir y pensar en función de los códigos de comunicación de em- presas y organizaciones cuyo propósito es particularmente comercial. - La estructura conceptual publicitaria de los negocios existentes en el área de estudio, se convierte en un modelo aspiracional para las generaciones más jóvenes, mismas que construyen un imaginario del lugar a partir de la oferta comercial de las marcas y negocios existentes. - El fenómeno publicitario y las implicaciones económicas que ello representa mediante el consumo de productos y servicios, contribuye significativamente con la pérdida de identidad de los lugares y espacios urbanos representativos de ciudades y comunidades, cuando no existen regulaciones cuyo cumplimiento implique el respeto por aquellos elementos que conforman la estructura urbana, su historia y sentido, o peor aún, cuando al existir regulaciones, estas subyacen al interés mercantil. Incluso, terminan por incidir de manera importante en la gestión y diseño de normas y demás elementos jurídicos tanto a nivel municipal como estatal destinados a la regulación del anuncio publicitario en el entorno urbano contemporáneo. - En la configuración del espacio urbano contemporáneo, subyace el criterio mercantil como una de las fuerzas de mayor capacidad en la gestión de cambios y adecuaciones a cualquier nivel. Las evidencias encontradas en el área de estudio, permiten dimensionar lo que ocurre a una escala mayor, y por lo tanto, nos obligan a la creación de acuerdos que permitan el rescate de la identidad del individuo y del espacio físico hacia criterios sostenibles e integrados con la realidad del planeta y los recursos naturales.

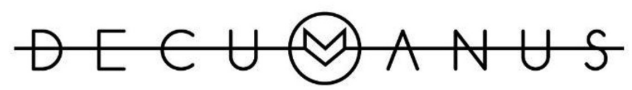

REVISTA INTERDISCIPLINARIA SOBRE ESTUDIOS URBANOS 


\section{Bibliografia}

Aprile, O. (2000). La publicidad estratégica. Barcelona, España: Paidós.

Baladrón Pazos, A. y Martínez Pastor, E. y. (2007). Publicidad y ciudad. La comunicación publicitaria y lo urbano: perspectivas y aportaciones. Sevilla, España: Comunicación Social.

Bueno, C. y Pérez, N. (2006). Espacios globales. México: Universidad Iberoamericana, Plaza y Valdés.

Caivano, J. (2005). Semiótica, cognición y comunicación visual: los signos básicos que construyen lo visible. Buenos Aires, Argentina: Universidad de Buenos Aires, Conicet.

Castells, M. (1974). La Cuestión Urbana. México: Siglo XXI Editores.

Castreje, S., Travieso, C., \& Zimmermann, B. (2 de junio de 2013). Hombre y espacio-BOLLNOW, Otto F. (1969). Recuperado el 7 de Julio de 2017, de IACGroup: http:/ / iacgroup.tumblr.com

Cordero, A.; Ochoa, L.; Núñez, Ó., \& Cordero, I. (2011). Manual de uso Lafayette. Distrito Demetria. Guadalajara, México: Montenegro Ediciones, Aquitectura Cordinada.

Eco, Umberto (2005). La estructura ausente. Introducción a la semiótica. México: De Bolsillo.

García Ramírez, F. (2002). Crónica de la publicidad en México. 1901-2001. México: Clío.

González, C. (2007). El significado del diseño y la construcción del entorno. México: Designio.

Ianni, Octavio (2006). Teorías de la globalización. México: Siglo XXI.

Ianni, Octavio (2004). La era del globalismo. México: Siglo XXI.
Leick, G. (2002). Mesopotamia. La invención de la ciudad. Barcelona, España: Paidós.

López Moreno, E. (2001). La cuadrícula: en el desarrollo de la ciudad hispanoamericana: Guadalajara, México. México: Universidad de Guadalajara, ITESO.

Lutz, B. (2010). La acción social en la teoría sociológica: Una aproximación. Argumentos, 23(64).

Maciel, P. (2012). Percepción social de la presencia de la publicidad exterior en la imagen del paisaje urbano contemporáneo. México: Universidad de Guadalajara.

Márquez, M. (2007). Análisis semiótico del concepto actual de belleza en la publicidad dirigida a la mujer. Sevilla, España: Universidad de Sevilla.

Rodríguez, J. \& Cota, M. (2006). La transformación económica en la Zona Metropolitana de Guadalajara y su impacto en el desarrollo urbano. México: Universidad de Guadalajara.

Ruíz, O. (2011). Análisis semiótico del signo publicitario en el centro comercial y su relación con la conformación de espacios urbanos globales. México: Universidad de Guadalajara.

Trifonas P. (2004). Barthes y el imperio de los signos. Barcelona, España: Encuentros contemporáneos. 